A. P. Bunger and B. Lecampion. Four critical issues for successful hydraulic fracturing applications. In X.-T. Feng, editor, Rock Mechanics and Engineering, Volume 5 (Surface and Underground Projects), Chapter 16. CRC Press/Balkema, 2017. (Author's manuscript).

\title{
Four Critical Issues for Successful Hydraulic Fracturing Applications
}

\author{
A. P. Bunger \\ Department of Civil and Environmental Engineering, University of Pittsburgh, Pittsburgh, PA, USA \\ Department of Chemical and Petroleum Engineering, University of Pittsburgh, Pittsburgh, PA, USA \\ B. Lecampion \\ Geo-Energy Laboratory - Gaznat Chair on Geo-Energy, EPFL-ENAC-IIC-GEL, École Polytechnique \\ Fédérale de Lausanne, Lausanne, Switzerland
}

\begin{abstract}
This paper reviews four critical mechanisms for successful applications of hydraulic fracturing that have emerged or grown in importance over the past 2 decades. These critical issues are managing height growth, decreasing near-wellbore tortuosity, predicting and engineering network versus localized growth geometry, and promoting simultaneous growth of multiple hydraulic fractures. Building on the foundation of decades of research relevant to each area but with an emphasis on advances within the past 20 years, the review presents available field evidence, laboratory data, and modeling insights that comprise the current state of knowledge. Fluid viscosity, injection rate, and in situ stresses are shown to appear as controlling parameters across all of these issues. The past contributions and limitations on future developments point to a future in which advances are enabled by a combination of fully coupled 3D simulations, advanced laboratory experiments, vastly expanded characterization capabilities, and order of magnitude improvements in monitoring resolution.
\end{abstract}

\section{INTRODUCTION}

Hydraulic fracturing for well stimulation initially entailed injection of relatively small volumes of fluid (gelled hydrocarbons or aqueous gel mixed with sand proppant) in order to bypass near wellbore damage in conventional oil reservoirs (Montgomery and Smith, 2010; Economides and Nolte, 2000, Chap. 5A). The technology evolved through its first 4 decades, the 1950s through the 1980s, bringing several changes. The fluid compositions transitioned from predominantly hydrocarbon-based to predominately water-based fluids, as summarized in the first review paper on hydraulic fracturing by Hassebroek and Waters (1964). The fluid volumes grew from the early, hundreds or thousands of gallons treatments to 250,000+ gallon treatments, with these larger stimulations carrying $\sim 1,000,000$ pounds of sand proppant, eventually targeting low permeability (unconventional) reservoirs (Montgomery and Smith, 2010).

Still, the evolution of the technology did not result in fundamental changes in the models used to simulate hydraulic fracture (HF) growth and guide engineering decisions. Throughout this period the basic elasto-hydrodynamic model set out in the early, seminal papers (Khristianovic and Zheltov, 1955; Perkins and Kern, 1961; Geertsma and de Klerk, 1969; Nordgren, 1972) and progressively generalized to obtain approximate but rapid simulation of HF growth via the socalled Pseudo 3D (P3D) method (Settari and Cleary, 1984), comprised the predominant directions of modeling innovation although the importance of modeling fully $3 \mathrm{D}$ fracture propagation was recognized early-on. These advances are well documented in past, model-oriented review articles (Medelsohn, 1984b,a; Adachi et al., 2007).

More recently, treatments have switched from exclusive application to vertical wells to widespread application for stimulation of horizontal wells. By the early 1990s the concept of generating multiple HFs from horizontal wells was being developed for targeting tight sandstone and shale 
reservoirs (Soliman et al., 1990). By the late 1990s success has been achieved in the Cotton Valley, Texas, using water with relatively small proppant concentration (Mayerhofer et al., 1997), bringing slickwater fracturing, developed in the 1950s (Harmon, 1957), to the mainstream . At this point, concepts of complexity of HF geometry and stress interaction between multiple branches of HFs were transitioning from infancy to childhood (see the review of Mahrer, 1999). Since then there has been a focus on topics including growth of HF networks (see Li, 2014, for a review of natural fractures in US shale plays), stress shadow interactions among multiple HFs distributed along horizontal wells, managing near wellbore tortuosity associated with initiation of HFs from horizontal wells, and fracture containment in shale reservoirs. While there exists some new terminology and the emphasis on these topics is unprecedented, all of these issues are appropriately understood in terms not only of the relevant contributions in the last decade but also with respect the roots each of these have in the classical hydraulic fracturing literature.

The goal of this review article is therefore to approach four critical issues for successful applications: 1) Managing hydraulic fracture height growth, 2) Decreasing near-wellbore tortuosity, 3) Predicting and engineering network versus localized growth geometry, and 4) Promoting simultaneous growth of multiple hydraulic fractures. While not purporting to be an exhaustive list of critical issues for successful applications, all of these have received unprecedented attention in recent years. Furthermore, all 4 issues are best viewed with a synthesis of model predictions, laboratory experiments, and field evidences, all the while setting each topic in its context from previous decades and highlighting some of the most relevant contributions and corresponding insights from the past 1-2 decades. Hence, this article is organized so as to highlight the importance and background for each topic followed by insights from modelling, field data, and laboratory experiments. Taken together these consideration give snapshot of the state of knowledge for each of these issues, giving rise naturally to proposed considerations for ongoing investigations.

\section{MANAGING HYDRAULIC FRACTURE HEIGHT GROWTH}

\subsection{Importance and Background}

Height growth refers to the growth of HFs in the vertical direction and therefore it relates to the propensity of HFs to cut through multiple strata. While sufficient height growth is necessary in order to contact the entirety of the targeted reservoir, excessive height growth is detrimental to the effectiveness of the treatments because it results in delivery of fluid and proppant to unproductive zones or, in an even worse scenario, in the stimulation of water bearing strata that result in increased water inflow to the well (e.g. Economides and Nolte, 2000). Height growth, which also is referred to as "fracture containment", has also been the topic of discussion in the context of preventing unwanted migration of fluids to strata that contain potable groundwater. This concern is potentially warranted in shallow wells that are separated by less than a hundred meters or so from groundwater resources; some coal seam methane wells are examples (e.g. EPA, 2004) as well as approximately one hundred/year high volume $\left(>10^{6}\right.$ gallons $)$, relatively shallow $(<3000$ $\mathrm{ft}$ depth) hydraulic fractures carried out in the U.S. (Jackson et al., 2015).

A seminal contribution in height growth prediction is Simonson et al. (1978). Their model is based on the equilibrium height of a plane strain cross section of a blade-shaped hydraulic fracture. That is, they look for the height at which the computed stress intensity factor, $K_{I}$, is exactly balanced by the stress intensity factor, $K_{I c}$, for each cross section of a hydraulic fracture that is long relative to its height $(\ell \gg H)$. In the limiting case of $K_{I c}=0$ they give an upper bound on the fracture height $(H)$ relative to the payzone height $\left(H_{\text {pay }}\right)$ that is implicit in the relationship

$$
\frac{p_{\text {net }}}{\Delta \sigma}=-\frac{2}{\pi} \operatorname{ArcSin}\left(\frac{H_{\text {pay }}}{H}\right)+1
$$

where $p_{n e t}$ is the difference between the fluid pressure and the stress opposing HF opening and $\Delta \sigma$ is the increase in compressive stress encountered between the payzone and the barrier. Equation (1) therefore represents an exact balancing of the stress intensity factor generated by the pressurization of the hydraulic fracture by the clamping stress generated by the elevated stress in the barrier region. This approach has been recently extended to account for equilibrium planar growth through up to 6 layers by Liu and Valkó (2015). 
While it has become generally accepted that stress contrasts between the reservoir and bounding layers is the most important factor determining height growth (Warpinski and Teufel, 1987; Nolte and Smith, 1981), the role of a variety of other factors were explored in the years that followed the work of Simonson et al. (1978). These include:

- High permeability bounding layers, which reduce the rate of height growth due to leakoff of fluid into the bounding layer (Quinn, 1994). Drawing on laboratory experiments, these barriers are thought to be effective when the permeability of the barrier layer is 3-4 times the payzone permeability (de Pater and Dong, 2009).

- Contrasting stiffness of layers, which impacts not only through the fact that stiffer layers tend to carry larger in situ stresses (e.g. Prats and Maraven, 1981), but also because they can impede crack growth (e.g. Simonson et al., 1978) and restrict fluid flow (van Eekelen, 1982; Smith et al., 2001). Nonetheless, it is generally considered that stiffness contrasts do not have substantial impact on height growth except through the impact on in situ stress (Abou-Sayed et al., 1984; Ben Naceur and Touboul, 1990; Gu and Siebrits, 2008).

- Weak bedding planes between the payzone and the bounding layer(s) that blunt or deflect fracture height growth (e.g. Daneshy, 1978b, 2009).

The following reviews the field, lab, and numerical evidences for the various conditions that limit height growth, highlighting the critical issue of current and ongoing research of the role of the weak bedding plane that often comprises the interface between the reservoir and the barrier layers above and/or below.

\subsection{Field Evidence}

Height growth is most often ascertained in the field indirectly - in contrast to direct observation from microseismic data. Most of this data is not published, and, of the published data, there is a tendency to publish plan views of event clouds that give no information about height growth. Furthermore, there may be a tendency to under-represent problematic height growth in the data that is actually published. Nonetheless, there are some useful examples in the literature that include:

- Barnett Shale: Several horizontal wells completed in the Lower Barnett formation exhibit hydraulic fracture growth that is contained within the Lower Barnett with a fracture height of $350 \mathrm{ft}$ (Fisher et al., 2004). In a compendium of otherwise mostly unpublished data from wells ranging in depth between about 4000-8500 ft, Fisher and Warpinski (2012) show height growth that is generally increasing with depth and that appears particularly prone to downward bias, especially at shallow depths. Davies et al. (2012) analyzed the data of Fisher and Warpinski (2012) and found that the median of all Barnett hydraulic fractures, without accounting for depth, is about $410 \mathrm{ft}$ with $10 \%$ of fractures exceeding $500 \mathrm{ft}$ in height above the injection point. Similarly, the median downward height growth is about $260 \mathrm{ft}$ with $10 \%$ of fractures exceeding $820 \mathrm{ft}$.

- Marcellus Shale: Two horizontal wells completed in the Lower Marcellus formation exhibit hydraulic fracture growth penetrating the $200 \mathrm{ft}$ thick combined Upper/Lower Marcellus, extending $150 \mathrm{ft}$ downward into the Onandaga formation and $250 \mathrm{ft}$ upward into the Skaneateles shale formation for a total fracture height of about $600 \mathrm{ft}$ (Mayerhofer et al., 2011). This example lies within the upper half of the range of heights in the data set of Fisher and Warpinski (2012) as analyzed by Davies et al. (2012), wherein the median upward height growth is about $410 \mathrm{ft}$ with $10 \%$ of fractures exceeding $820 \mathrm{ft}$. The median downward growth is found to be about $100 \mathrm{ft}$ with $10 \%$ of fractures exceeding about $160 \mathrm{ft}$.

- Eagle Ford Shale and Woodford Shale: Based on the data of Fisher and Warpinski (2012), Davies et al. (2012) find the median upward growth in both formations to be around $60 \mathrm{~m}$ with $10 \%$ of fractures exceeding $115 \mathrm{~m}$. The downward growth is less in the Eagle Ford, with a median value of $160 \mathrm{ft}$ and $10 \%$ exceeding $490 \mathrm{ft}$ compared to the Woodford with a median value of $230 \mathrm{ft}$ with $10 \%$ exceeding $650 \mathrm{ft}$.

- Bakken Shale: Dohmen et al. (2013) present data indicating typical 400-500 ft fracture height for 2 wells completed in the Middle Bakken formation. An additional $\sim 200 \mathrm{ft}$ of downward growth is observed in some cases and many cases are accompanied by clusters of events about $800 \mathrm{ft}$ above the top of the Middle Bakken that are attributed to activation of initially fluid-filled faults. Dohmen et al. (2014) use a similar monitoring method and argue that the data evidence 
the stress shadow from previous stages is able to increase height growth. (See further discussion of stress shadow in Section 5.)

- Haynesville Shale: Warpinski (2014) presents a case of a stimulation that traverses the 100 $\mathrm{ft}$ thick Haynesville formation, growing to at least $330 \mathrm{ft}$ above and $160 \mathrm{ft}$ below for a total fracture height of about $590 \mathrm{ft}$.

Besides inferring height growth from microseismicity, it is also possible to obtain measurements using tracers that either tag the fluid or the proppant. For example, Saldungaray et al. (2012) present several case studies where fracture height in vertical wells is measured at the wellbore using either Compensated Neutron (CNT) or Pulsed Neutron Capture (PNC) tools that detect proppant in which a high thermal neutron capture compound is incorporated, leading to a reduced neutron count rate over the propped portion of the hydraulic fracture. As a further example, Hammack et al. (2013) present results wherein Perfluorocarbon tracers were injected along with hydraulic fracturing fluids in a well completed in the Marcellus formation. Monitoring of overlying Upper Devonian wells ranging from 3000-4000 ft above the Marcellus well confirmed that there was no measurable fluid migration during hydraulic fracturing and in the 8 month monitoring period that followed.

Direct observations of hydraulic fracture height growth are limited to shallow formations, namely coal seams, in which hydraulic fractures are placed and subsequently exposed as mining proceeds. While it is important at the outset to realize that shallow coal seam reservoirs typically have lower magnitude vertical stress relative to the horizontal principal stresses than in most deeper formations, there are nonetheless some important insights that can be gained. Most strikingly, these minethrough experiments not only show containment - i.e. arrest of growth in the vertical direction at the contact between the coal and the roof/floor rock, Figure 1a - but also they show deflection along the horizontal contacts especially when the bounding formation is stiffer and/or stronger than the coal, Figure 1b (Elder, 1977; Lambert et al., 1980; Diamond and Oyler, 1987; Jeffrey et al., 1992). Furthermore, these minethrough experiments enforce an appreciation of the complications associated with predicting hydraulic fracture growth in the presence of multiple layers. For example, hydraulic fractures are observed to cross thin layers even if they are stiff/strong and they are observed to grow on top of the contact above a thin stiff layer that is separated from a thick stiff layer by a thin soft layer (Figure 1c) (Lambert et al., 1980; Diamond and Oyler, 1987; Jeffrey et al., 1992, 1995).

Additionally, naturally-occurring dikes that form as fluid-driven cracks and which are mechanical analogues to hydraulic fractures, have been observed to cross, arrest, or deflect when they encounter potential barriers (Figure 2) (Gudmundsson et al., 1999; Gudmundsson and Loetveit, 2005; Gudmundsson, 2011), producing similar geometric observations as for hydraulic fracture minethrough experiments in coal seams.

\subsection{Laboratory Investigations}

Experiments in gelatin have demonstrated dependence of hydraulic fracture growth through a contact between two layers on the relative material properties, especially the stiffness (Rivalta et al., 2005; Kavanagh et al., 2006, see review in Rivalta et al. 2015). The persistent challenge, though, has been to obtain analogue experiments for the case of stress contrasts. This analogue is important because simulations suggest stress contrasts are the most important factors determining height growth (Warpinski and Teufel, 1987; Nolte and Smith, 1981; Warpinski et al., 1982).

El-Rabaa (1987) presents a comprehensive laboratory parametric study using sandstone, limestone, marble, and hydrostone specimens. These experiments demonstrate the tendency of hydraulic fractures to favor growth in lower stress zone as well as the apparent suppression of height growth by weak interfaces (after the prediction of Daneshy, 1978a). However, they do not entail sharp stress jumps as expected at many lithological boundaries, but instead they obtain a smoothlyvarying applied stress across the eventual plane of HF growth. In fact, obtaining a closer analog to geomechanical layering is challenging to achieve because simply constructing a system with layers of contrasting stiffness and loading the specimen on its boundaries generates spurious shear stresses along the layer contacts. In one early investigation, Johnson and Cleary (1991) portray contrasting cases of radial growth and fixed height, with height growth completely restricted, but this study does not investigate finite height growth. 


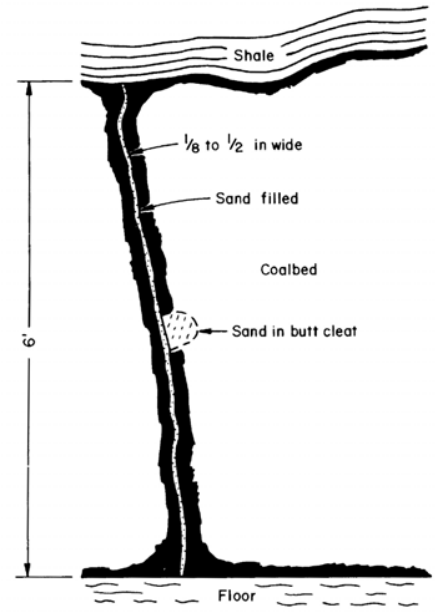

a)

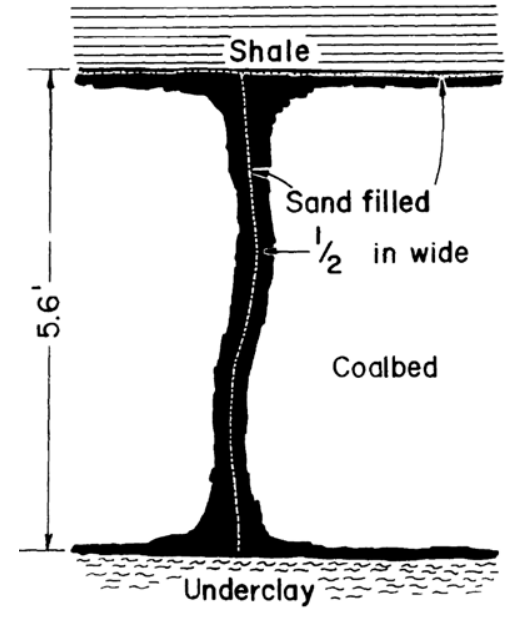

b)

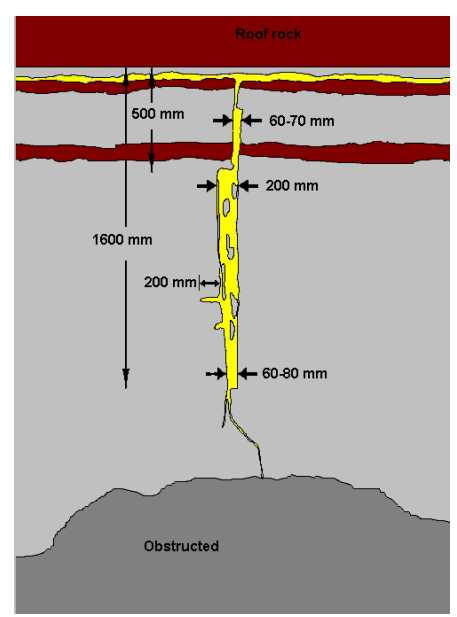

c)

Figure 1. Mapped hydraulic fractures in coal showing: a) Arrest at relatively stiff/strong roof and floor layers, from Diamond and Oyler (1987), b) Formation of a horizontal component along the contact between the coal seam and a relatively stiff/strong roof rock, from Diamond and Oyler (1987), c) Direct crossing of the stiff/strong but thin layer between two coal layers and growth of a horizontal component above a relatively stiff/strong layer that is separated from the stiff/strong roof rock by a relatively thin layer of soft/weak coal, redrawn after Jeffrey et al. (1992) (all figures after Rivalta et al., 2015, with permission).

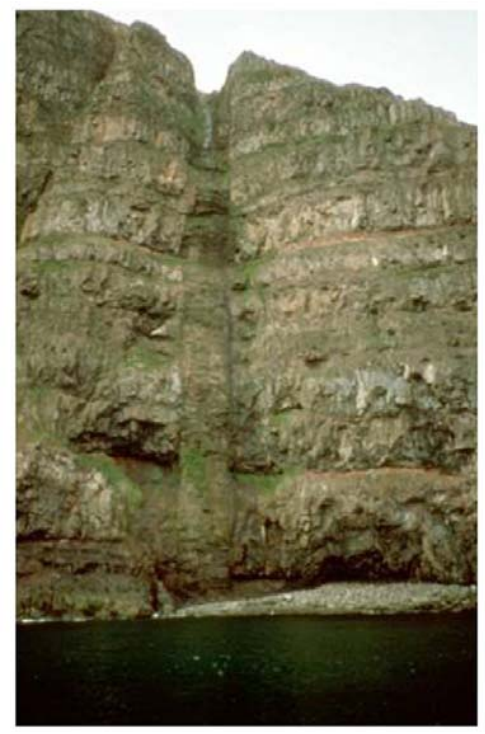

a)

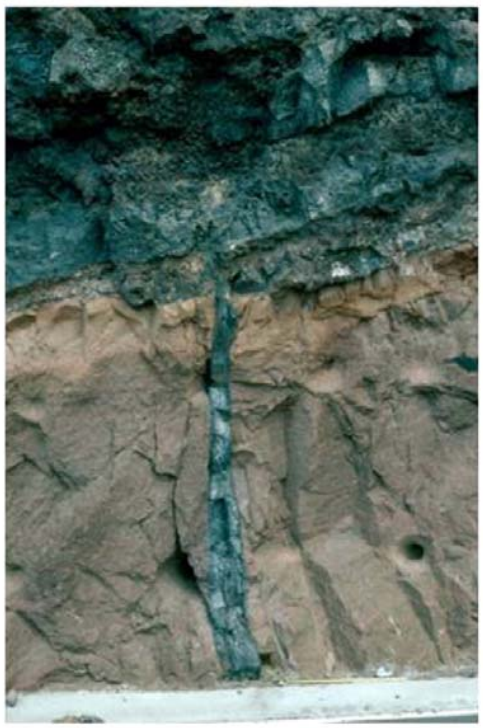

b)

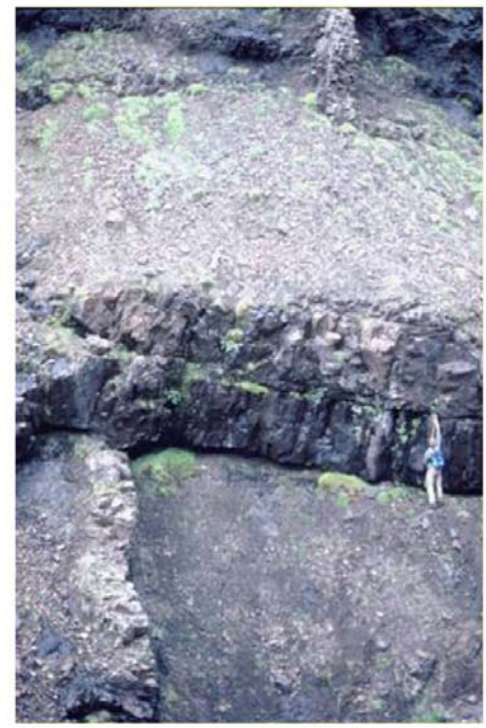

c)

Figure 2. Dike interactions with layered geological media. a) A vertical, 6-m-thick dyke the penetrates a sequence of lava flows in North Iceland. b) A vertical, 0.3-m-thick dyke that arrests at the contact between a pyroclastic layer and a basaltic lava flow in Tenerife, Canary Islands. C) The dyke that deflects along the contact to form a sill between a basaltic sheet and a lava flow, Southwest Iceland. From Gudmundsson (2011) (after Rivalta et al., 2015, with permission).

More recent experiments make use of PMMA specimens that are machined with surface profiles such that a prescribed stress profile is generated when the blocks are pressed together (Jeffrey and Bunger (2009), Figure 3a). These experiments show the contrast between moderate height growth when a low stress reservoir zone is bounded by higher stress barriers (Figure 3b) and preferential growth into a low stress layer that bounds the reservoir layer (Figure 3c). These experiments have provided benchmarks that have been used in the development of numerical simulators (e.g. Wu et al., 2008; Dontsov and Peirce, 2015). 

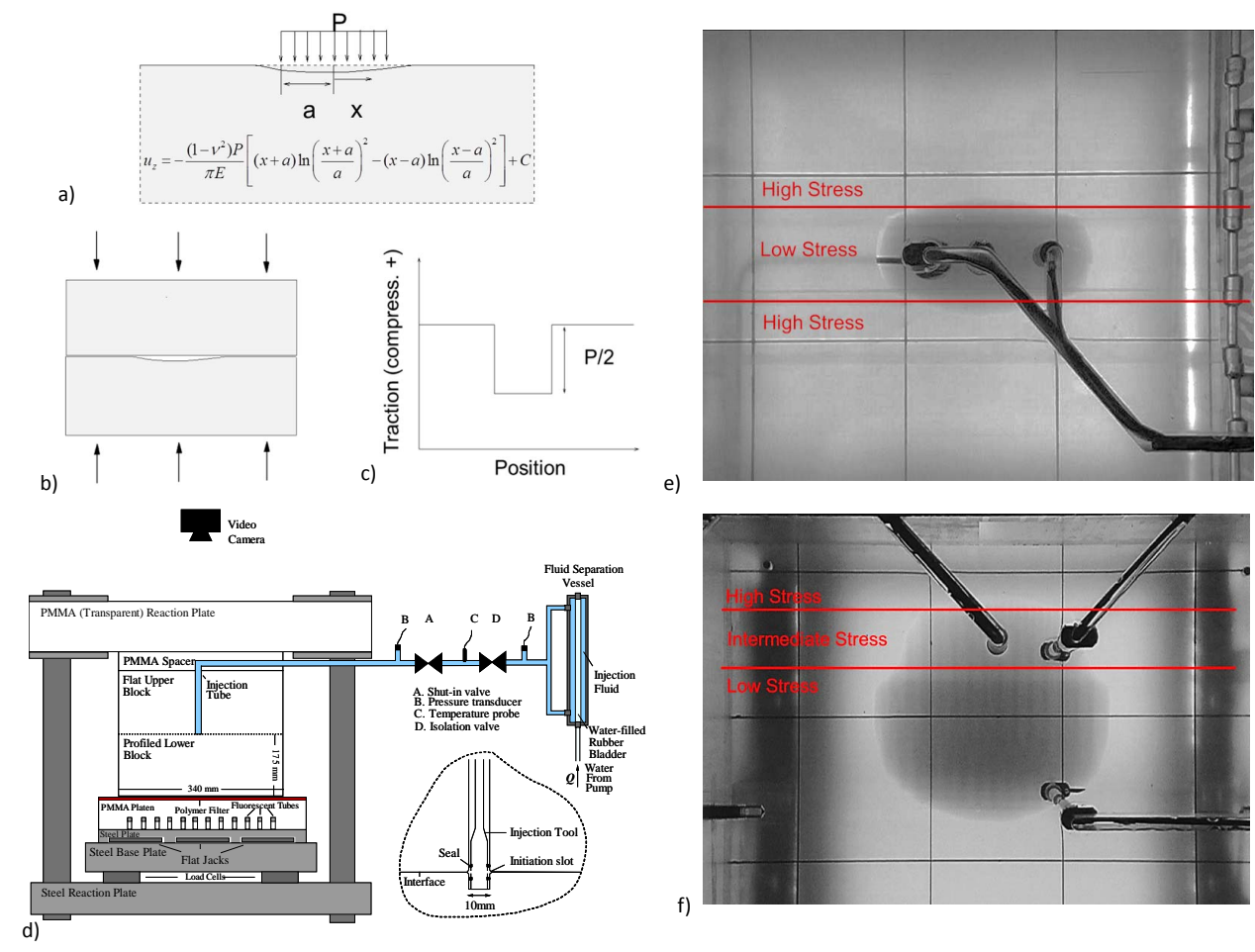

Figure 3. Laboratory experiments on height growth (after Jeffrey and Bunger, 2007; Wu et al., 2008; Jeffrey and Bunger, 2009). a-c) Illustration of the method used to generate the stress jump by machining block surface(s) to the solution for the displacement due to a uniform strip loading, d) Laboratory apparatus used for the experiments, e) Moderate height growth into higher stress bounding layers, f) Preferential growth into a low stress layer.

\subsection{Modeling Insights}

The shortcomings of Pseudo 3D models in modeling height growth have been recognized early on (e.g. Medelsohn, 1984a) and motivated the developments of Planar 3D models for HF design in the early 90s (e.g. Ben Naceur and Touboul, 1990; Advani et al., 1990). The most obvious area for improvement of Pseudo 3D is the handling the role of the layered geology ubiquitous to the sedimentary basins in which oil and gas deposits occur. The challenges are illustrated by comparison of the experiments of (Figure 3b) with Pseudo 3D ("P3D", e.g. Settari and Cleary, 1984) predictions (Wu et al., 2008; Dontsov and Peirce, 2015). The comparison also includes predictions of the simulator ILSA (Implicit Level Set Algorithm, Peirce and Detournay, 2008), which is a planar 3D simulator accounting for full 3D elasticity and generalized growth (relative to P3D) of a planar hydraulic fracture. From this comparison it is apparent that P3D severely overestimates height growth in the viscosity dominated regime and, conversely, underestimates height growth in the toughness dominated regime. Dontsov and Peirce (2015) use this comparison to argue the necessity for enhancements to the modeling approach that seek to maintain the rapid computation of $\mathrm{P} 3 \mathrm{D}$ while better approximating the 3D elasticity relationships and the equations governing the advance of the hydraulic fracture front.

Even in the case of a fully coupled planar 3D hydraulic fracture simulation, the restriction of fracture growth to a single plane may often miss the role of the layering in determining height growth. Indeed there is ample evidence from direction observation, such as Figures 1 and 2, for arrest, offset, and/or deflection of hydraulic fractures at the margins between layers. The most obvious reason for the deflection along these boundaries is relative weakness of the contact (e.g Daneshy, 1978b, 2009; Abbas et al., 2014). However, weak contacts are almost certainly not the 


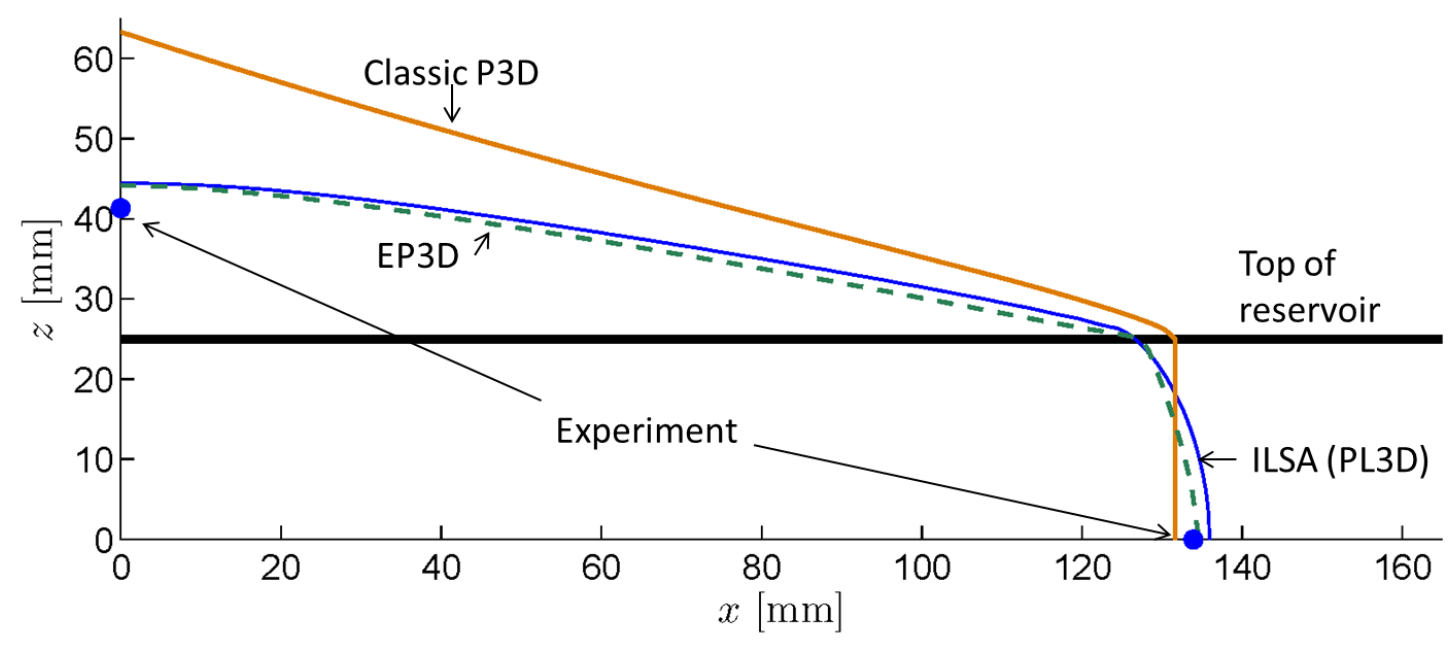

Figure 4. Comparison of fracture shape for pseudo 3D (P3D) and Planar 3D (ILSA PL3D) predictions with the experiments from Figure $3 b$ at time=604 seconds (modified from Dontsov and Peirce, 2015, courtesy of E. Dontsov).

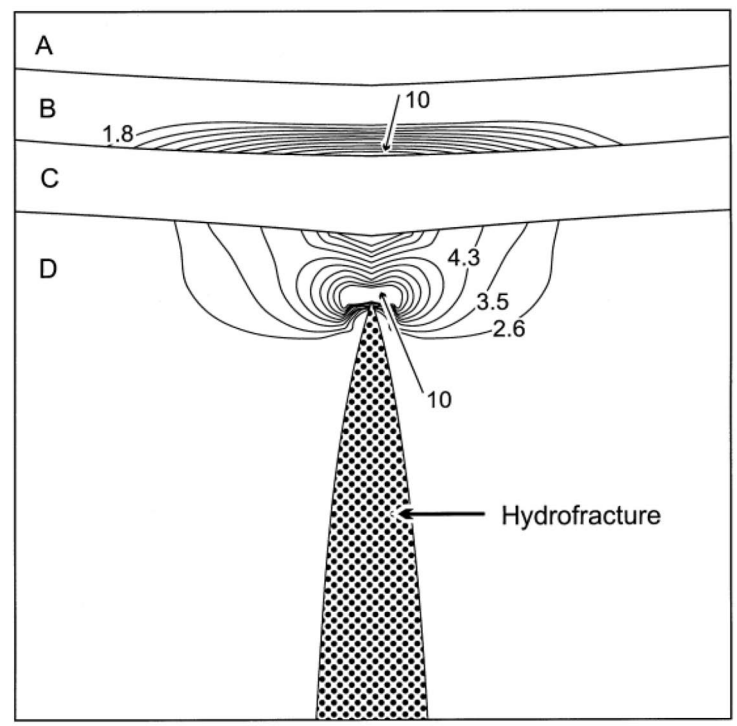

Figure 5. Reduction of fracture induced stress by a thin, soft layer, illustrated by contours of maximum principal stress. Layers B and D (100 GPa) are much stiffer than Layers A and C (E=1 GPa) (From Gudmundsson and Brenner, 2001, with permission).

only cause of deviation to T-shaped growth. Very thin layers of relatively soft rock (Young's modulus 1-2 orders of magnitude smaller than surrounding rock) have been shown through modeling to dissipate the near crack-tip tensile stresses, thus leading to arrest of height growth and subsequent transition to T-shaped growth (Figure 5). While these authors were concerned with the related problem of arrest of ascending dikes, a similar mechanism could be the cause of the horizontal component of the hydraulic fracture forming below a thin layer of soft coal separating two layers of stiffer and stronger rock portrayed in Figure 1c.

While the impact of thin, soft layers should arguably receive more attention than it has to date, many consider the weakness of the interface between the reservoir and a potential barrier layer to be its defining characteristic. Indeed the ability of weak interfaces to suppress hydraulic fracture height growth has been long-recognized (e.g. Daneshy, 1978b; Teufel and Clark, 1984). However, implementation of mechanisms associated with interaction with a weak interface into hydraulic fracture simulators has accelerated substantially in the past 1-2 decades. The common thread of predictions is that a weak enough interface subjected to a low enough vertical stress (i.e. normal stress across the horizontal interface) will cause it to suppress height growth. In essence 
this principles is accounted for in the early works on hydraulic fracture interaction with natural fractures (Blanton, 1982; Warpinski and Teufel, 1987; Renshaw and Pollard, 1995). However a range of approaches have been developed that place varying degrees of emphasis on the strength of the interface or the coupled fluid flow problem that arises in hydraulic fracturing. The classical Renshaw and Pollard (1995) criterion provides the interface strength-focused end member as it essentially compares the ability of a frictional interface to transmit a fracture-induced tensile stress that is sufficient to nucleate a crack on the opposite side of the interface. This criterion was adapted for prediction of fracture containment by Gu et al. (2008). On the other hand, Chuprakov et al. (2013) and Chuprakov et al. (2014) present a criterion for HF crossing of natural fractures that depends on fluid flow and is therefore sensitive also to the permeability of the nature fracture, and this has been adapted for prediction of height growth by Chuprakov and Prioul (2015).

Even when the hydraulic fracture is able to cross a weak interface to grow in height into an overlying or underlying layer, the growth through the weak interface can lead to offsets. Offsets have been shown to also suppress height growth. This result is anticipated through the reduction of stress intensity at the fracture tips (Sheibani and Olson, 2013) and can be shown to reduce height growth by around $10 \%$ for offset angles of $60-70$ degrees and by $20 \%$ or more for offset angles of 80-90 degrees (Abbas et al., 2014).

\subsection{State of Knowledge}

Indirect observations of height growth are valuable but also possessing important caveats. Microseismic events that locate out of zone could be the result of location error and, even if located appropriately, the connection to fluid flow is not direct and there is no indication of whether proppant reached that location. On the other hand, fluid tracer studies provide information for only one point and cannot comment on whether fluid reached other out-of-zone locations. Furthermore, tagged proppant is limited in that it only indicates the propped portion of the hydraulic fracture and only at the wellbore itself; it is possible that the height indicated by tagged proppant $\operatorname{logs}$ at the wellbore greatly overestimates the height at a short distance from the wellbore.

The observations of Dohmen et al. (2013) regarding activation of events by perturbing initially fluid-filled faults in the Bakken Shale raises another important caveat. While events are generated remotely, the timing suggests they are not associated with hydraulic fracture growth but rather pressure disturbance of the fluid already within the fault. A similar observation is given by Hammack et al. (2013) for a well completed in the Marcellus Shale. These can lead to reported fracture heights in data sets based on furthest extent of events, such as Fisher and Warpinski (2012), that are not attributable to height growth per se or, for that matter, to hydraulic fracture growth along a fault. These can be essentially remotely triggered events through stress and/or pore pressure perturbation. Hence the reported ranges of fracture heights based on microsiesmicity are potentially misleading in these cases of fault activation.

Ambiguities and uncertainties motivate direct observation and modeling. Laboratory experiments experiments show P3D can overestimate height growth, thus motivating alternatives that preserve the rapid computation of $\mathrm{P} 3 \mathrm{D}$ but that improves accuracy. Field experiments, albeit in relatively shallow formations such as coal seams, nonetheless demonstrate the importance of layers and the bedding planes between layers. Hence, these direct observations point toward the importance of ongoing efforts to appropriately account for the impact of layering and discontinuities on height growth.

\section{DECREASING NEAR-WELLBORE TORTUOSITY}

\subsection{Importance and Background}

In all applications, HFs are initiated from a wellbore drilled down to the target reservoir formation. Most of the time, the well is cased and cemented but so-called open-hole completion are also used. The location of the initiation point of the hydraulic fracture is controlled in most cases by detonating a set of shaped charges. It results in a number of perforation tunnels penetrating in the formation. The length of the perforation gun tool dictates the length of the well interval perforated (typically from 5 to 30 feet). In the case of a cemented wellbore, the perforation tunnels go through casing, cement and rocks and are the only possible "entry" points for the injected fluid into the formation. Abrasive jetting is also sometimes used in order to create an initiation flaw in the 


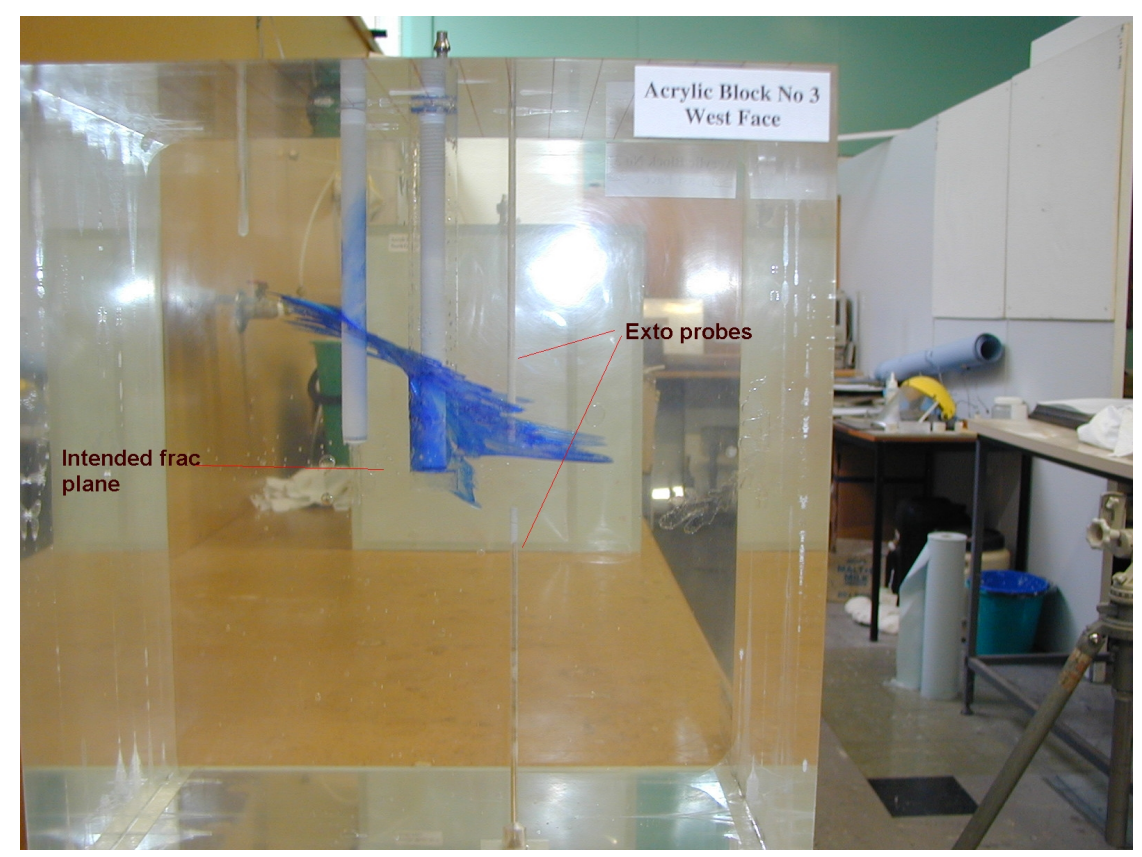

Figure 6. Complex HF geometry in the near-wellbore region exhibiting completion interface debonding (micro-annulus), re-orientation toward the far-field preferred fracture plane with fracture front segmentation due to mixed mode fracturing (Photo courtesy of Rob Jeffrey \& Jean Desroches). Experiments performed in PMMA with a Newtonian fracturing fluid.

rock. Even with all the possible care, it is difficult in practice to optimally create a flaw such that the hydraulic fracture initiates and propagates directly from the wellbore in the direction of the preferred in-situ stress orientation.

Another option is not to create any flaws, therefore relying on defects in the rock but to limit the interval where a fracture can initiate by ensuring that the fluid can pressurized (and penetrate) the formation only over a finite interval of the well. For the case of an open-hole wellbore, this can be achieved by using a fracturing completion string, inflating packers to isolate a given zone of the well and pumping the fluid through a tubing. In cased and cemented wellbore, cemented sleeves can be used in conjunction with packers / plug systems on coil-tubing for example. The HF then initiates in the region controlled by near-wellbore stress concentration, which depends primarily on the orientation of the well with respect to the in-situ stresses but also the geometry of the created flaws if any (perforations or notch). The presence of cement (and its quality) can also play a significant role: interface debonding can occur thus providing more open-hole like conditions even for a cased and cemented wellbore (Weijers and de Pater, 1992; Behrmann and Nolte, 1999).

After initiating, the HF rotates from the local near-wellbore stress concentration toward its farfield preferred plane of propagation governed by the in-situ stress field. The extent of the region over which such a re-orientation takes place has been found experimentally to be about two to five times the wellbore radius. It is important to bear in mind that the fracture re-orientation toward the preferred far-field stress direction is not always smooth, as illustrated by the laboratory example shown in Figure 6. The reason is that mode II and III stress intensity factors (shear and tearing modes in addition to the opening mode I) may develop during re-orientation leading to curving and possibly segmentation of the fracture front. Depending on the wellbore and perforations orientation, several distinct fractures may initiate with different orientation (e.g. along the axis of the well and transverse to the well, or nearly parallel in the case of a deviated well) with a dominant one further propagating in the far-field with some merging and others not (Behrmann and Elbel, 1991; Weijers et al., 1994). Of course, in the case where the far-field stresses are close to one another (e.g. similar horizontal stresses), the orientation of the fracture in the far-field is not constrained. Multiple fractures initiating from the wellbore have been observed in the laboratory as a result in such case (Doe and Boyce, 1989). 
The directly-measurable consequence of near-wellbore fracture tortuosity is often an increase in the pumping pressure. Such a larger pressure - often referred to as near-wellbore entry friction or near-wellbore pressure loss - can be simply understood. If an HF is not oriented in the direction favored by the in-situ stress in the near-wellbore region, during its re-orientation the local normal stress acting on the fracture faces can be locally larger than the minimum in-situ stress. This larger local normal stress directly increases the fluid pressure required to open and propagate the HF. Depending on the details of the fracture tortuosity (for example smooth versus highly irregular with several fracture branches), pinch-points can develop with possible detrimental consequences on the placement of proppant. The proppant can bridge at such pinch-points, then possibly packing back to the wellbore and causing a near-wellbore screen-out. When this happens slurry can no longer enter the fracture, the injection pressure exponentially increases and the injection has to be stopped. However, a high treating pressure does not necessarily imply a higher risk of nearwellbore screen-out. The degree of the pressure increase and the associated width restriction is related in a non-trivial manner to the degree of complexity of the HF(s) geometry in the nearwellbore as well as to treatment parameters. For example, higher viscosity and injection rate directly increase the near-wellbore pressure loss, but appear to also play a role on the development of the near-wellbore fracture geometry.

Several mitigation techniques to reduce near wellbore tortusity have been put forward in practice (sometimes combined). These include: 1) oriented perforating (or notching) to try to reduce re-orientation and complex fracture geometry in the near-wellbore region, 2) injection of acid/sand-slugs/gel slugs after formation breakdown to erode the near-wellbore tortuosity and/or 3 ) the use of highly viscous fluids to generate sufficient fracture width to avoid near-wellbore screen-out. The following reviews field evidence, laboratory experiments, and modeling insights for the presence and mitigation of near wellbore tortuosity.

\subsection{Field Evidence}

The presence of near-wellbore fracture tortuosity is typically inferred indirectly from pressure records and diagnostic tests characterizing entry friction. Direct observations are limited to the trace of the fracture on the wellbore wall as observed by image logs performed after fracturing, of which little examples have been published (see Jeffrey et al. (2014) for one such example).

The near-wellbore entry friction can be quantitatively assessed by performing a so-called stepdown test (during a single-entry treatment). Such a test consists in lowering the injection rate by steps during fracturing from the initial constant injection rate to zero while recording the treating pressure (ideally downhole at the level of the perforations). At least four to five steps are required in order to decipher between a classical perforation friction term associated with the choking effect of the holes in the casing and another non-linear term associated with near-wellbore fracture tortuosity (see Economides and Nolte (2000), chapter 9, pages 9-32 / 9-33 for details). Large nearwellbore friction associated with fracture tortuosity have been reported for both vertical (Roberts et al., 2000) and horizontal wells (Kogsbøll et al., 1993; Desroches et al., 2014; Pandya and Jaripatke, 2014, among others).

Another indirect line of evidence to detect near-wellbore tortuosity is the reduction in treating pressure often observed after injection of acid, sand/gel slugs, or even just proppant. Acid, sand or gel slugs appear to erode the near-wellbore tortuosity therefore reducing the near-wellbore pressure loss. Examples of reduction of 1000 psi or more are typical (Cleary et al., 1993; Kogsbøll et al., 1993; Chipperfield et al., 2000; McDaniel et al., 2001).

Analysis of treatments in wells drilled in the same formation but with different deviation (from vertical) have shown a correlation between larger fracturing pressure and well deviation (Veeken et al., 1989). Correlation between horizontal well azimuth and fracturing pressure have also been reported (Owens et al., 1992) with larger fracturing pressure observed for wells in the direction of the minimum stress (with axial HFs re-orienting to transverse in the far-field). However, without step-down tests, it is difficult to conclude that higher than expected treating pressure necessarily indicates larger near-wellbore tortuosity. Interestingly, in vertical wells in the Cooper basin Australia, large near-wellbore pressure losses associated with fracture tortuosity do not correlate at all with either the treating pressure (fracture gradient) or the measured stress magnitude (Mc Gowen et al., 2007). It appears in that particular case that natural micro-cracks (i.e. rock fabric) are mostly 
responsible for large near-wellbore pressure losses. Neither sand slugs, acid nor oriented perforating were actually $100 \%$ successful in reducing near wellbore pressure losses in that particular case.

Jeffrey et al. (2014) reports a field study for open-hole vertical wells (in a stress regime favoring horizontal fractures) notched via abrasive jetting to promote the initiation of transverse fractures from the well directly. Multiple single entry treatments were performed and image logs were run post-frac. Axial (vertical in that case) fractures were found on image logs for a number of treatment despite the transverse notch. However, the breakdown pressures did not significantly differ between cases where an axial or a transverse fracture initiated, higher near-wellbore friction were consistently observed when axial fractures were detected on image logs. This is a typical example of the effect of re-orientation from an axial fracture in the near wellbore to a transverse fracture in the far-field.

Large difference in near-wellbore pressure losses between single-entry fracturing jobs performed in the same horizontal well (completed with cemented sleeves and drilled in the direction of the minimum stress) have been reported in Desroches et al. (2014). Although the formation was found to be very homogeneous along the horizontal section, variations in near-wellbore tortuosity-related pressure drops of more than 1,000 psi (at the same injection rate) between fracture treatments were reported. Such large variation may be due to the cemented sleeve system (i.e. whether or not debonding occurs away from the sleeve) or just small scale rock fabric heterogeneities that have not been characterized.

There are a number of examples showing the benefit of oriented 180 degree perforating (i.e. the technique of orienting a line of perforations in the preferred far-field fracture plane) in reducing fracturing pressure in the case of vertical wells (Manrique and Venkitaraman, 2001; Behrmann and Nolte, 1999). An accuracy of 20 to 30 degrees of the orientation of the 180 degree perforating guns has been found to be sufficient to avoid large friction (Behrmann and Nolte, 1999). Uncertainty on stress direction is such that 60 degree phasing is often found to be operationally more robust while still providing reasonable results for proppant placement (e.g. Ceccarelli et al., 2010). Oriented perforating is more complicated for deviated wells, and even more so for horizontal wells due to the intrinsic limitation of the perforation tool geometry. Nonetheless, some benefits have been reported in wells up to 65 degree deviation (Pearson et al., 1992; Pospisil et al., 1995). For horizontal well drilled in the direction of the minimum stress, the accepted best practice is to cluster perforations over a rather short interval (i.e. the perforations can not lie within a single plane in that case); multiple fractures that may or may not all link up away from the wellbore are to be expected (Behrmann and Nolte, 1999). The use of oriented abrasive jetting has been found beneficial in a number of cases. For both vertical and a horizontal well, abrasive jetting has allowed the placement of proppant in difficult situations (e.g. highly stress formation etc.) as discussed in McDaniel and Surjaatmadja (2009); Ceccarelli et al. (2010). It is not always successful, though, depending on rock fabric effects (Strain, 1962) or cleaning issues (Jeffrey et al., 2014).

Finally, the practice of using highly viscous fluid has been found beneficial in a number of cases (Aud et al., 1994; Hainey et al., 1995). Higher viscosity creates more width for proppant transport and are also though to help promoting a dominant single fluid path in the near-wellbore.

\subsection{Laboratory Investigations}

HF near-wellbore tortuosity can be observed in detail in the laboratory, although the scaling of the effect of the perforations, casing and cement is far-from trivial especially knowing the quasibrittle behavior of rocks and the inherent size effects associated with failure of those materials. Nevertheless, a number of laboratory experiments (Daneshy, 1973a; Veeken et al., 1989; Doe and Boyce, 1989; Weijers et al., 1994; Behrmann and Elbel, 1991; Abass et al., 1996; Fallahzadeh et al., 2014) have documented the effect of wellbore, in-situ stress misalignment and magnitudes as well as the presence of perforations (see Fig.7 for a summary). The deviation of HF from simple axial and planar fracture were first observed by Daneshy (1973b) in the laboratory for slightly deviated wells.

One important aspect (often overlooked in early contributions) relates to the completion sequence of block test investigating the effect of cemented completion. It is particularly important to cement the casing while the block is already loaded. Doing otherwise greatly enhances the bonding stress between the casing/cement and the block. Initiation at the tip of the perforations is always favored 
a) Vertical well

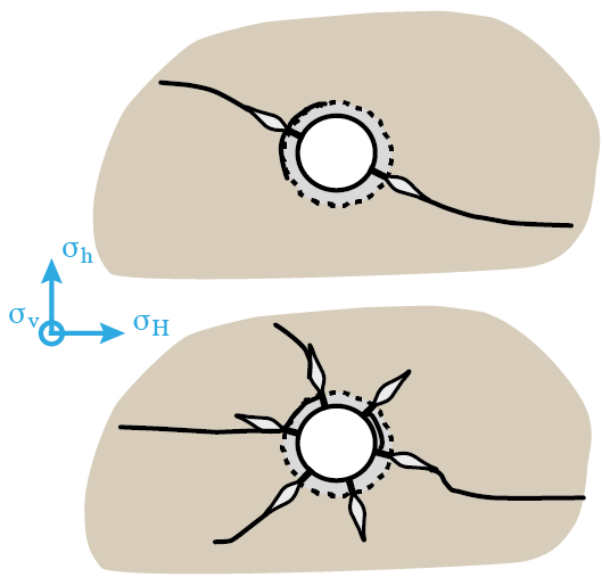

b) Horizontal well

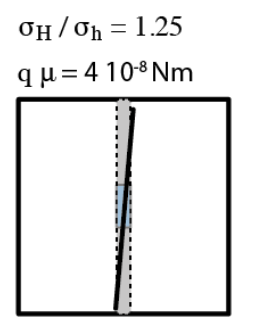

$\sigma_{\mathrm{H}} / \sigma_{\mathrm{h}}=2$

q $\mu=310^{-6} \mathrm{Nm}$

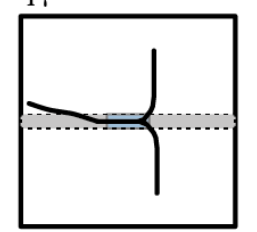

$\underset{\sigma_{\mathrm{v}}}{\sigma_{\mathrm{H}}^{\sigma_{\mathrm{H}}}} \sigma_{\mathrm{h}}$

$\sigma_{\mathrm{H}} / \sigma_{\mathrm{h}}=1.25$

$\sigma_{\mathrm{H}} / \sigma_{\mathrm{h}}=1.25$

q $\mu=710^{-7} \mathrm{Nm}$

q $\mu=210^{-8} \mathrm{Nm}$
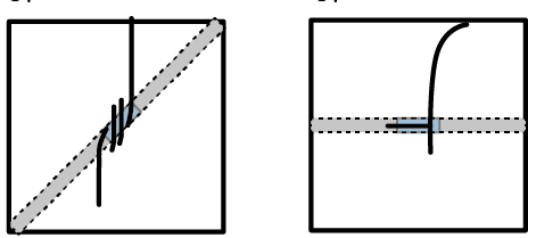

$\sigma_{\mathrm{H}} / \sigma_{\mathrm{h}}=1.25$

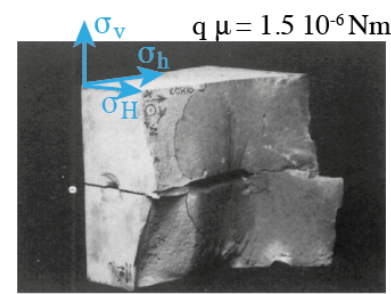

c) Deviated well

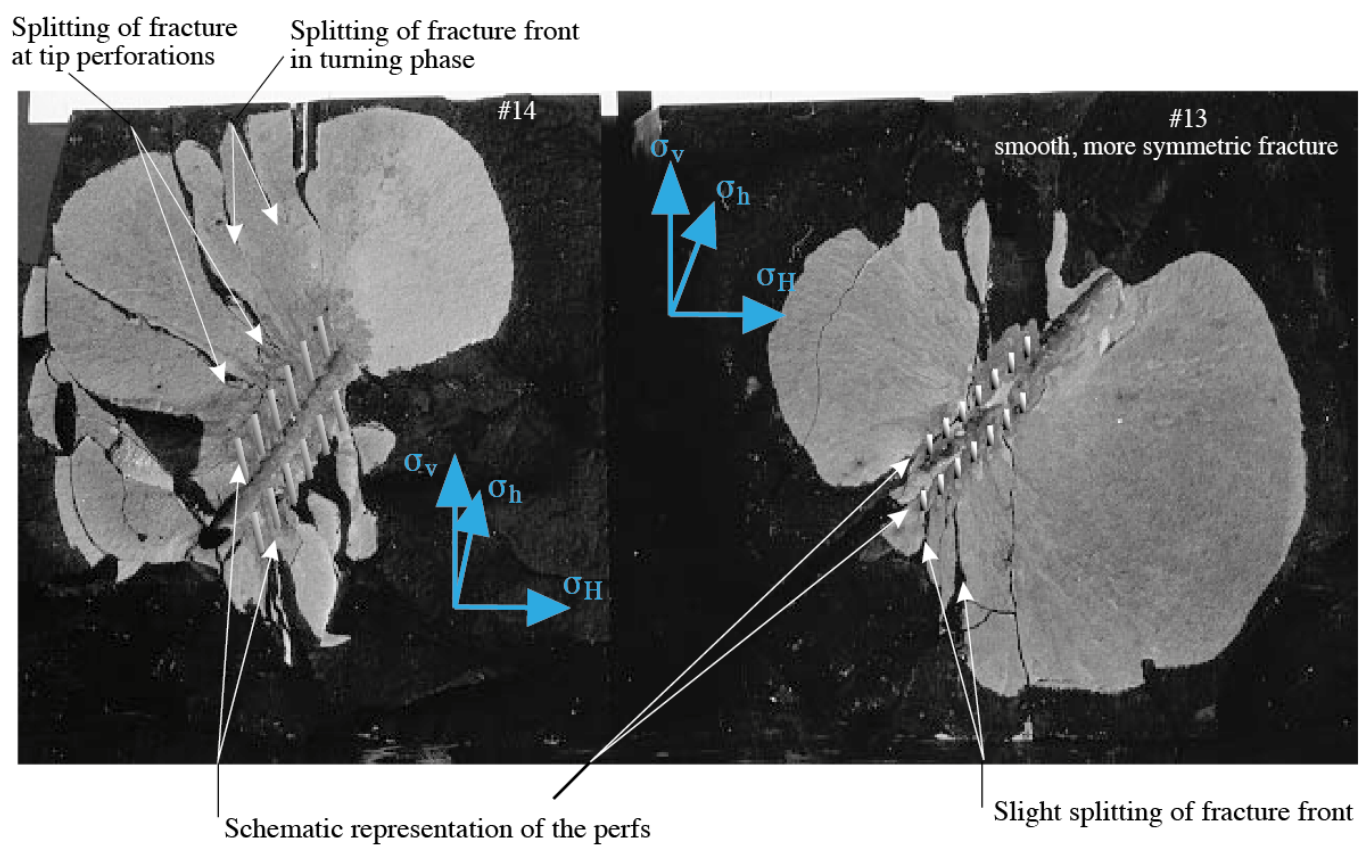

Figure 7. Schematic examples of near-wellbore fracture tortuosity. a) fracture(s) re-orientation due to misalignment of 180 or 60 degree phasing perforating in a vertical well. b) effects of horizontal well azimuth, horizontal stress ratio and fluid effect (injection rate $q$ times viscosity $\mu$ ) on the initiation of axial or/and transverse fracture(s) - Open-hole experimental results of Weijers (1995) (horizontal trace of the created HFs $5 \mathrm{~cm}$ above the plane containing the horizontal wellbore). c) Fractures surfaces for two strictly similar experiments: initiation from a cemented deviated well (49 degree deviation, 60 degree azimuth from the preferred far-feild fracture plane) with top/bottom lines of perforations (van de Ketterij and de Pater, 1999; van de Ketterij, 2001), casing debonding occurred during experiment \#14 (which also exhibited lower pressure) but not during experiment \#13. Complete mixed mode (I, II and III) fracture propagation with fracture front splitting is more severe for experiment \#14 (adapted from van de Ketterij and de Pater (1999), reproduced with permission).

as a result, whereas fluid debonding of these interfaces might occur in reality when the bonding stress is lower (see Weijers and de Pater, 1992, for examples and discussion).

A large experimental effort was performed at TU Delft in the 1990s during the early stage of highly deviated and horizontal wellbore developments (Weijers and de Pater, 1992; Weijers et al., 
1994; van de Ketterij and de Pater, 1997; van de Ketterij, 2001). Besides the effect of stress and wellbore misalignment (Figure 7b), injection rate and viscosity were found to play an important role. The re-orientation of axial fracture into transverse fractures appear more gradual and smooth in the case of larger viscosity/rate (see Weijers et al. (1994) for discussion). It is also worthwhile to remember that maximum pressure (breakdown) is increasing substantially with viscosity and rate for similar conditions (e.g. Weijers et al., 1994; Detournay and Carbonell, 1997; Lecampion et al., 2015). Care must therefore be taken not to link higher treating pressures necessarily to higher fracture tortuosity. In that respect, the example of two strictly similar experiments (denoted as \#13 and \#14 in van de Ketterij and de Pater (1999)) for a fully deviated well is particularly striking (see Figure 7c). The resulting fracture surface for experiment \#14 is quite complex exhibiting multiple fracture fronts splitting during the re-orientation from a more axial fracture to the well to the far-field preferred plane of propagation. In comparison, the fracture of experiment \#13 is smoother during its reorientation and more symmetric. Interestingly, experiment \#13 exhibits a maximum pressure about $8 \mathrm{MPa}$ larger than experiment \#14. The main difference between the two experiments is due to debonding of the casing/cement/block interfaces in experiment \#14 (see van de Ketterij and de Pater (1999) for more details and discussion). This example highlights the complex interactions between stress-orientation, fluid infiltration and mixed mode fracture propagation in the vicinity of the wellbore.

It is important to note that higher injection rate and viscosity tends to promote a dominant fluid pathway compared to low viscosity and rate which allows a more uniform pressurization of the different defects. It ultimately results in the creation of different fracture geometries in the near-wellbore: e.g. higher injection rate and viscosity have also been found to decrease fracture tortuosity in experiments performed in a pre-fractured medium (Beugelsdijk et al., 2000).

It is worth mentioning that laboratory experiments in homogeneous rock with slotted/notched wellbores in the direction of the preferred far-field fracture plane typically did not report any fracture tortuosity which makes slotting an attractive technique (Surjaatmadja et al., 1994; Chang et al., 2014). The impact is also shown to be more pronounced for longer slots. In a recent study (Burghardt et al., 2015), the effect of rock fabric (mineralized natural fractures and weak bedding planes) was shown to be significant in some cases, especially natural fractures in the near-wellbore region can arrest HF initiating from some slots and create significant tortuosity, a result consistent with some of the field observations described in Mc Gowen et al. (2007).

\subsection{Modeling Insights}

Most modeling efforts entail only a static stress-analysis in order to discern the highest stress location and fracture initiation pressure depending on the geometrical configuration of the well, perforation and far-field in-situ stress (e.g. Alekseenko et al., 2012; Li et al., 2015, among many others). This unfortunately does not provide information on the actual degree of fracture tortuosity to be expected, and the associated pressure loss during fluid injection. In an analytical study, Weng (1993) has combined stress analysis and fracture mechanics arguments for the link up of fractures initiating at different perforations (but neglecting fluid flow) and provided some rationale for engineering perforation design. Other authors pre-suppose the fracture geometry to compute the corresponding pressure drop (see e.g. Cherny et al., 2009, for 2D plane-strain simulations). Such computations, however, do not provide any information on the parameters affecting the development of HF near-wellbore tortuosity.

Coupled simulations of HF propagation and re-orientation from the wellbore accounting for elastic deformation, fluid flow in the newly propagating fractures are rare. Under plane-strain conditions (2D), Zhang et al. (2011) report an extensive numerical study applicable to the case of a vertical well. Their results show that a HF initiating from a defect misaligned with the minimum stress curves toward the preferred fracture plane over one a distance of about two wellbore radius (consistent with experimental observations). They have also introduced and verified dimensionless numbers that control the re-orientation in either toughness or viscosity dominated propagation regimes. These dimensionless numbers combine the minimum and maximum horizontal stress, $\sigma_{h}$ and $\sigma_{H}$, respectively, with the fracture toughness of the rock $\left(K_{I c}\right)$, the radius of the wellbore $(R)$, the injection rate $\left(Q_{o}\right)$, the fluid viscosity $(\mu)$, and the plane strain elastic modulus of the rock $\left(E^{\prime}\right)$. This dimensionless number is given by $\left(\sigma_{H}-\sigma_{h}\right) \sqrt{R} / K_{I c}$ in the toughness dominated regime (negligible viscosity), and by $\left(\sigma_{H}-\sigma_{h}\right) \sqrt{R} /\left(12 \mu Q_{o} E^{\prime 3}\right)^{1 / 4}$ in the viscous dominated regime of propagation (which is typically of more practical relevance). Fracture re-orientation occurs 
over shorter distance for larger value of such dimensionless parameter, with one practical consequence being that initiating HF with higher viscosity and injection rate leads to a more gradual re-orientation. A result consistent with the experimental observations of Weijers et al. (1994). Their simulations also display significant increase of wellbore pressure (up to $25 \mathrm{MPa}$ ) during further propagation for sharper re-orientation. The authors have also investigated the effect of multiple possible initiation flaws. In those cases, multiple HFs initiate then re-orient and compete with one main HF finally dominating in the far-field.

Three dimensional fully coupled near-wellbore HF simulations are very limited. Carter et al. $(1999,2000)$ were able to partly compare their results to some of the experiments of Weijers et al. (1994) but were not able to reproduce crack front segmentation as observed experimentally (see Figures $7 \mathrm{~b}$ and $\mathrm{c}$ ). This was recognized to be associated with the lack of a robust propagation criteria accounting for combined tensile and anti-plane shear propagation (mode I and III). Properly capturing such a mixed mode of propagation in 3D coupled with fluid flow remains a challenge today. Recent numerical modeling reported by Sherman et al. (2015) provide a step in that direction.

\subsection{State of Knowledge}

Although, the main causes for HF tortuosity in the near-wellbore region are now well recognized (well/perforations/in-situ stress misalignment, fluid viscosity and injection rate), detailed quantitative predictions of the complex 3D HF geometry in the near-wellbore and its impact on fracturing pressures and screen-out risk remains a challenge. The main fundamental difficulties lie i) in a good prediction of 3D mixed mode propagation - especially mixed mode I, II and III which leads to fracture front break-up - combined with ii) proper fluid-solid coupling in complex 3D fracture geometry. Both are needed in order to better understand the impact of stress, well orientation and treatment parameters on near-wellbore fracture geometry. One has however to keep in mind experiments \#13 and \#14 of van de Ketterij and de Pater (1999), which although strictly similar yielded widely different fracture re-orientation due to casing de-bonding. Small heterogeneities (difficult to characterize) at the scale of the wellbore may possibly play a large role in the development of the fracture geometry in the near-wellbore.

Practically today, the best technique to quantify near-wellbore tortuosity problem is via diagnostic tests (e.g. step-downs). Estimation of near-wellbore entry friction can then be used in order to subsequently refine the stimulation design (e.g. Gulrajani and Romero, 1996). Depending on the situation some mitigation measures (for example sand-slugs, oriented perforating, and high viscosity fluid) may or may not work. Careful trial of these different techniques combined with properly performed diagnostic tests remains today the most pragmatic approach to address near-wellbore tortuosity problems and lower the risk of early screen-out.

\section{PREDICTING AND ENGINEERING NETWORK VERSUS LOCALIZED GROWTH GEOMETRY}

\subsection{Importance and Background}

Generation of complex networks of hydraulic fractures is a relatively new concept. Its current form arose out of field trials in the Barnett Shale, Texas, in the late 1990s and early 2000s wherein multiply-branched HFs were inferred from lineaments of microseisms (Maxwell et al., 2002; Urbancic and Maxwell, 2002; Warpinski et al., 2005). An example of evidence of networklike growth is given by Figure $8 \mathrm{a}$, where the contrast to microseismic data taken to imply simpler, bi-wing geometry, Figure 8b, is clear.

These observations became profoundly influential. For starters, successful production of gas from the Barnett Shale - the first major success in hydrocarbon production from shale reservoir was presumed to be tied to the large contact surface generated by this "complexity" (e.g. review of King, 2010). Hence, the practice began for low permeability gas, and later oil, wells of quantifying the so-called "Stimulated Reservoir Volume" (SRV), which is essentially the volume of reservoir within a box that contains most of the microseisms generated by a stimulation (from Warpinski et al. (2005), although the concept and terminology was apparently developed previously for Enhanced Geothermal Systems, e.g. Kruger and Yamaguchi (1993)). SRV, or more specifically the width of the box defining what eventually because known as SRV, was found to correlate with 


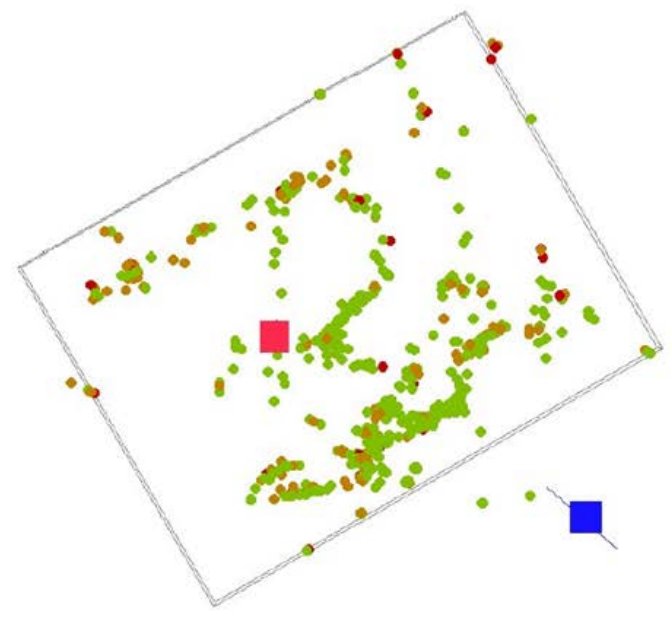

a)

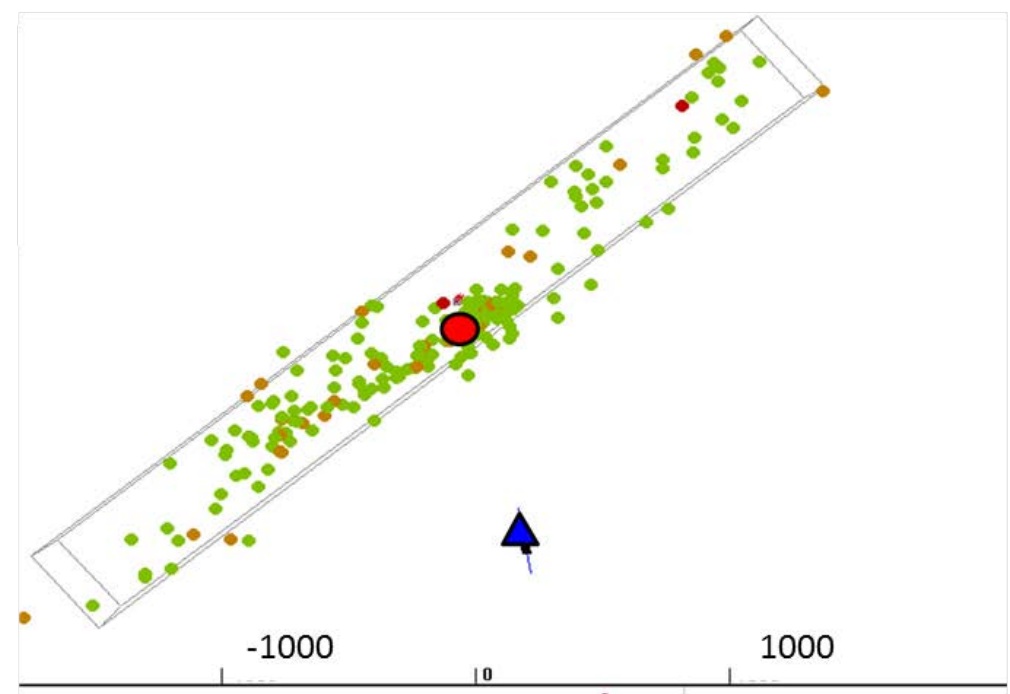

b)

Figure 8. Microseismic data for vertical wells in the Barnett Shale. a) Example of network growth (from Maxwell et al., 2002, with permission). b) Example of simple geometry (from Urbancic and Maxwell, 2002, with permission). In both cases the scale is shown in feet, the red square/circle indicates the well and the blue square the monitoring well.

production for Barnett Shale wells by Fisher et al. (2002) and it therefore its size became a metric of success of a stimulation.

As the concept of "complexity" and the measurement of SRV took hold in the industry, significant effort was aimed at development of models to predict HF growth in reservoirs with a preponderance of natural fractures (NFs). Concomitantly, previous studies of fracture intersection with natural fractures were brought to the forefront. Not only were new models for predicting HF growth in NF reservoirs considered vital for optimizing stimulation in the Barnett Shale, but also the expansion of shale gas and oil development to other plays was driving a need to understand basic conditions for network versus localized growth. This section is aimed at summarizing the basic conditions for network growth that have been identified through these efforts.

\subsection{Field Evidence}

Network growth is perhaps most strikingly shown in microseismic data from vertical well stimulation in the Barnett Shale, Figure 8a (Maxwell et al., 2002). This data set shows distinct, parallel 

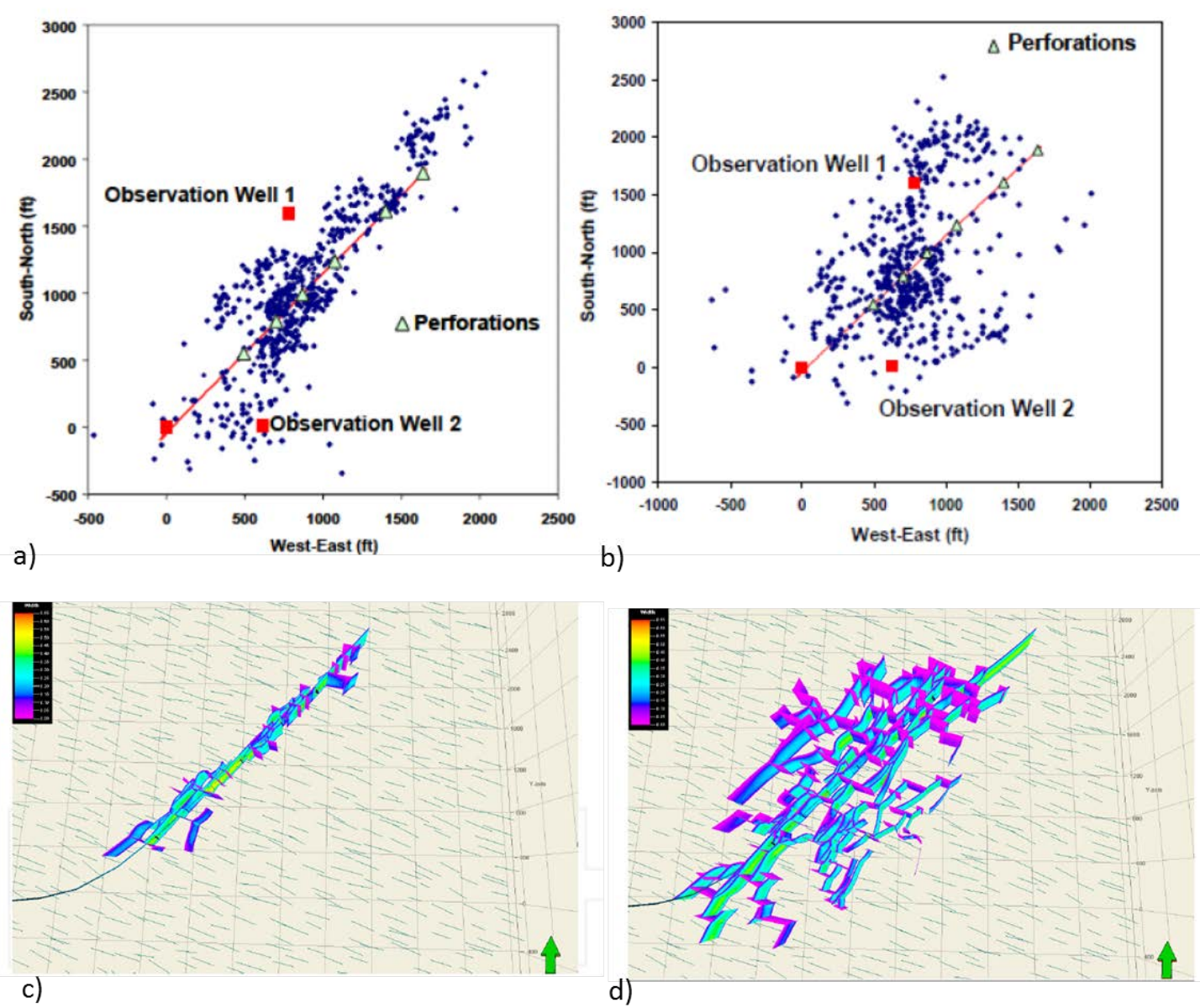

Figure 9. Images of microseismic data (a-b, from Warpinski et al. (2005), with permission) and numerical simulations (c-d, from Kresse et al. (2013)) for a horizontal wells in the Barnett Shale. Contrasting cases of presumably-localized gel fractures (left, a and c) and presumably network-like water fracture (right, b and d).

lineaments connected by oblique lineaments, thus forming the inferred network of HFs. There are some important features common to these early field studies. The first is that all involve injection of water rather than higher viscosity gel-type fluids. Indeed, in complimentary work, Warpinski et al. (2005) contrast water and gel stimulation for a horizontal well, again in the Barnett Shale. They show a larger microseismic cloud for the treatment that used water (Figure 9a-b). This result, along with several other studies showing superior production from water fractures (e.g. Mayerhofer et al. (1997) and see review in King (2010)), became cornerstones for the argument in favor of water fractures in situation where a network of fractures is desired. It is, however, important and often overlooked that use of water seems to be necessary but not sufficient for network growth, even in the Barnett; two of the six examples presented by (Urbancic and Maxwell, 2002) indicate relatively simple, bi-wing geometry.

A second observation of these early Barnett studies is that the lineaments tend to be distinct and separated by several hundred feet. The spacing between the lineaments is therefore similar to the fracture height. Furthermore, the distinction of the lineaments is warranted via microseismic events because their separation is far greater than the typical, tens-of-feet location uncertainty.

A third observation is that evidence for network growth comes almost exclusively from the Barnett Shale. One reason is that nearly all shale stimulations in other formations have entailed injection to entry points separated by tens of feet distributed along horizontal wells. Hence, the nominal fracture spacing and the location uncertainty are approximately the same so that a complex fracture and single-stranded fracture are indiscernible from the available data. Another possible explanation lie in the fact that the Barnett Shale exhibit nearly equal in-situ horizontal 
stresses compared to other US shale basin; larger in-situ deviatoric stresses constraining fracture growth to a dominant plane.

In spite of a growing trend towards predictions of complex growth from models and assumption of complex growth underlying the generation of microseismic clouds, direct observation of hydraulic fractures shows arguably simpler tendency. Core-through data from the Multiwell/MSite Project, Piceance Basin, Colorado (Northrop and Frohne, 1990), shows a cluster of 30 fracture strands covering an interval of about 4 feet. Of these, about 10 strands contain a white substance presumed to be dehydrated gel and 4 dominant strands contain clumps of 6-10 sand grains presumed to be residual proppant (Warpinski et al., 1993). On the one hand, this finding comprised one of the first and most influential evidences of HF complexity, and similar multi-stranded morphology has been observed in core-through HF mapping in other basins (Fast et al., 1994). Nonetheless, it is important to realize that the complexity only covered a section a few feet in width and therefore comprises an observation at a completely different scale than the hundredsof-feet scale of complexity that comprises the focus of discussions since the Barnett Shale studies (e.g. Urbancic and Maxwell, 2002). Furthermore, even this very localized complexity has been argued to comprise a worst case scenario due to the specific conditions in the Piceance Basin (Nolte, 1993). Also note that microseismic clouds generated by growth of similar (but subsequent) HF experiments in this basin are on the order of 100 feet in width Warpinski et al. (1996), which is on the order of the location uncertainty and, based on comparison with the several feet of width of the "complexity" observed for previous treatments, is not likely to be an indicator of with width of the stimulated zone.

Direct observation of HFs is also available from experiments in which hydraulic fractures are placed in orebodies or coal so that the HFs are exposed by mining activities. For example, Jeffrey et al. (2009) find that propped HFs in a heavily-fractured and faulted orebody are typically found in single, quasi-planar strands. Occasionally two, and at one point three, strands were observed. But secondary strands are always of limited persistence. Furthermore, the observed fracture orientation is consistent overall with the orientation of the minimum in situ stress, with limited offsets perturbing HS to stair-stepping geometry. In general, then, the observed HFs are not network like in this minethrough experiment, and this is in contrast to the predicted complexity from a DFNtype HF simulator (Rogers et al., 2011). Moreover, persistence of network-like propped fractures are yet to be observed in spite of the experience of other mine through experiments in both hard rocks (e.g. van As and Jeffrey, 2000; Jeffrey et al., 2009; Bunger et al., 2011) and coal (e.g. Elder, 1977; Lambert et al., 1980; Diamond and Oyler, 1987; Jeffrey et al., 1992, 1995).

\subsection{Modeling Insights}

Numerical explorations provide one means of discerning the conditions favoring network growth. Three main conclusions can be drawn from available results:

1. Network growth is promoted when the horizontal stress components are equal and is increasingly suppressed as the relative difference is increased (Olson and Dahi-Taleghani, 2009; Kresse et al., 2013).

2. Low viscosity fluids will be the most amenable to network growth while high viscosity fluids will be the most amenable to forming a single dominant hydraulic fracture (e.g. Kresse et al., 2013), Figure 9c-d.

3. The continuous joints should be oblique to the minimum stress direction (Olson and DahiTaleghani, 2009; Cipolla et al., 2011).

\subsection{Laboratory Investigations}

Besides these basic conditions, one of the critical observations from simulators is that the predicted HF geometry strongly depends on the criterion used to determine whether an HF will cross or be deflected when it encounters an NF, especially for simulating injection of high viscosity fluids (Kresse et al., 2013). This observation is a strong motivation for laboratory experiments aimed at understanding the mechanisms governing HF-NF interaction. In these experiments, a common theme is that HF crossing NFs is promoted by larger differential stresses (Warpinski and Teufel, 1987; Llanos et al., 2006; Gu et al., 2011; Bunger et al., 2015). In this regard, HF lab experiments are similar to the "dry" crack experiments of Renshaw and Pollard (1995) (R\&P). However, there are important distinctions. 


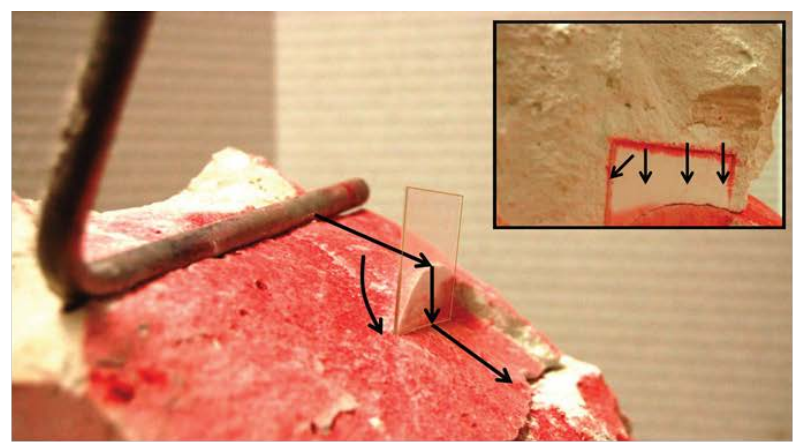

a)

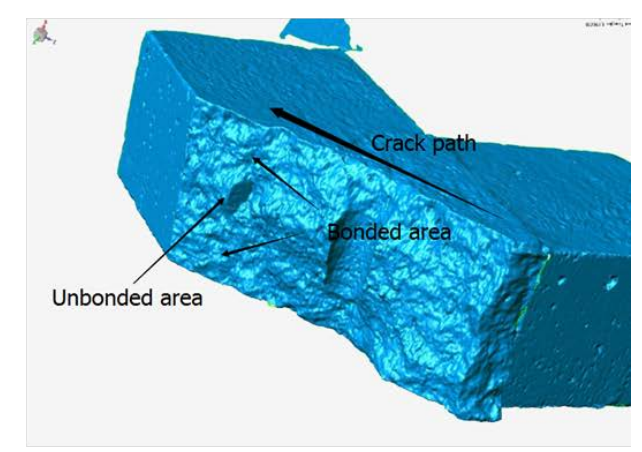

b)

Figure 10. Figure illustrating HF engulfing smaller discontinuities. a) HF path diverting around a strong inclusions (glass inclusion in hydrostone), from Olson et al. (2012). b) Digitized HF path showing offset as it engulfed a debonded region of an otherwise bonded natural fracture in a mortar specimen, from Fu et al. (2015).

Firstly, experiments with fluid driven cracks do not show dependence on friction coefficient as in the theory and experiments of R\&P (Bunger et al., 2015). Furthermore, use of high viscosity fluids promote localized growth relative to low viscosity fluids in fractured block experiments (de Pater and Beugelsdijk, 2005). Hence, attributing the role of stresses would seem to not be related to the impact on the frictional strength of the interface. Rather, as discussed by Bunger et al. (2015), the stresses impact on the permeability of the interface, which is probably more relevant for fluid-driven cracks (and which is accounted for, for example, via the model of Chuprakov et al. (2014)). In support of the impact of stress on network growth, note also that under conditions of 300 psi vertical stress and zero horizontal stresses, Abass et al. (1990) observe extreme complexity at laboratory scale in blocks of coal, while Suarez-Rivera et al. (2013) demonstrate that HF paths are more directed and ostensibly less "complex" when shale laboratory specimens are subjected to increasing horizontal stress differences.

In summary, one theme is that lab experiments indicate that fluid flow plays a vital role in determining whether HFs will cross or deflect to NFs. A second, emerging theme is that HF-NF interaction often entails mechanisms and geometries that are not readily captured by $2 \mathrm{D}$ models. For example, ultrasound monitoring indicates NF-parallel (i.e. out-of-plane for a 2D model) growth of the HF prior to crossing when initially circular HFs approach discontinuities Bunger et al. (2015). Growth that is initially halted by a discontinuity is also inferred from laboratory experiments with HFs interacting with relatively strong and high permeability (compared to gypsum matrix) sandstone lenses (Blair et al., 1990). But perhaps the most striking is the ability of an HF to engulf hard inclusions (Olson et al., 2012) or weak discontinuities (Bahorich et al., 2012; Fu et al., 2015), as illustrated in Figure 10. This ability to bypass discontinuity is undoubtedly a contributor to persistence of HFs through fractured and otherwise heterogeneous rocks. Furthermore, it is incompatible with the typical assumption of models, particularly 2D and pseudo 3D models, that NFs persist with uniform properties through the full height of the reservoir with uniform properties.

\subsection{State of Knowledge}

While it is broadly agreed that isotropic stress, low viscosity fluid, and natural factors that are oblique to the principal stress direction are basic ingredients for network growth, there are many unresolved issues. These include the role of leakoff and proppant transport. But these issues can be addressed by models that include more coupled physical processes and or make fewer geometric restrictions. In essence these are solvable problems with a series of extensions to existing approaches. There are, however, at least two issues that pose deeper challenges. The first stems from limitations on existing monitoring. Microseismic monitoring cannot distinguish between network and localized growth when entry points are spaced similarly to the location uncertainty (tens of feet). But besides direct observation, such as core through or mine through mapping, microseismic monitoring is the most direct and by far the most commonly applied method for inferring hydraulic fracturing growth geometry in the field. Problematically though, its resolution 
limits can leave models predicting simple versus complex growth geometry with similar degrees of model-data agreement.

Secondly, a drive toward including more physical processes and or more geometric complexity in models is inevitably a drive toward more required characterization. But some critical parameters are nearly impossible to characterize. Perhaps most notable of problematic parameters is the size (i.e. extent) of natural fractures and other heterogeneities in the reservoir. NF characterization is currently performed from well logs and it is not possible to discern the extent of a fracture from its intersection with the wellbore.

Taken together, these challenges make network versus localized growth prediction one of the most challenging issues in hydraulic fracturing. Overcoming these challenges will require 3-D models that are informed by characterization that includes natural fracture(s) strength, permeability, orientation, and size. Moreover, Most importantly, though, monitoring must be improved so as to definitively benchmark models using direct observation from offset wells and/or from microseismic monitoring with an order of magnitude better resolution than is currently available.

\section{PROMOTING SIMULTANEOUS GROWTH OF MULTIPLE HYDRAULIC FRACTURES}

\subsection{Importance and Background}

Multiple hydraulic fracture growth from a horizontal well was first inferred from microseismic monitoring by Fisher et al. (2004), making it one of the most recent major developments in hydraulic fracturing. They observe "multiple linear features at roughly 500 foot spacing," compared to roughly 300 foot fracture height, "regardless of perforation cluster location." Their observations show that injection from a horizontal well can lead to multiple HF growth, which is distinct from network growth in that fractures are fed directly by the wellbore rather than by forming a network with other fractures. Hence, in its simplest form, multiple HF, as referenced here, consists of an array of planar and parallel HFs.

Following early observations, simultaneously generating multiple HFs has now become the essential goal of multistage HF treatments, particularly those using the so-called plug and perforate method. In this approach, the wellbore is divided into intervals on the order of hundreds of feet in length. Clusters of perforations are placed within these intervals. Typically there are 3-6, 2 foot long clusters of perforations holes distributed with roughly 30-100 feet of separation between them. The desired result is uniform stimulation resulting from uniform distribution of the fluid and proppant among the entry points (perforation clusters). This section describes data and modeling efforts aimed at discerning the degree to which uniform distribution is achieved and, in turn, devising approaches to improve the uniformity of stimulation associated with multiple simultaneous HF growth from horizontal wells.

\subsection{Modeling Insights}

The emergence of multiple HFs growing with a spacing that is $\sim 1.2-2.5$ times the fracture height, as observed by Fisher et al. (2004), corresponds to an energy-minimizing geometry for an array of simultaneously-growing HFs (Bunger, 2013). In essence, this energetically-preferred spacing emerges from a competition. On the one hand, the HFs avoid growing very close to each other (relative to the fracture height) because more energy is required in order to overcome the elevated stresses caused by the fractures' neighbors (as previously pointed out by Fisher et al., 2004, among other). But, opposing this tendency to avoid growing near one another, minimization of energy dissipation associated with viscous fluid flow drives the system to split the fluid among all possible growing HFs (Bunger, 2013). The result of this competition is an energetically preferred spacing of 1.2-2.5 times the fracture height, where closer spacing in within this range corresponds to cases with larger pressure losses across the perforations (Bunger et al., 2014).

In this context, current practice of multistage HF invariably places perforation clusters close to each other relative to the fracture height. The mechanical impact of the close proximity is typically referred to as "stress shadow, and has been associated with:

1. Tendency of the growth of central fractures to be suppressed due to the higher stress in the central part of the array compared with the ends (e.g. Germanovich et al., 1997; Fisher et al., 2004; Olson, 2008; Abass et al., 2009; Meyer and Bazan, 2011; Kresse et al., 2013; Wu and Olson, 2013; Lecampion et al., 2015), see example in Figure 11a. 
2. Deflection of the HF path toward the regions of lower stress (e.g. Roussel and Sharma, 2010, 2011; Bunger et al., 2012; Sesetty and Ghassemi, 2013; Wu and Olson, 2013; Daneshy, 2015) or, in some cases, complete re-orientation due to fracture-induced changes in the principal stress directions (Roussel et al., 2012).

Note that there is a coupling between these behaviors; Daneshy (2015) shows that the nonuniformity of the growing hydraulic fractures can impact the deflection of their paths. The deflection/curving of simultaneously growing HFs also appears to be suppressed when the difference between the two horizontal stresses increase (e.g. Xu and Wong, 2013; Lecampion et al., 2015).

Besides predicting the challenges associated with stress shadow effects, models have been used in conjunction with field experience to suggest approaches that can promote multiple HF growth from horizontal wells. Some promising techniques include:

1. Limited Entry: This approach for horizontal wells draws inspiration from decades of application for multi-zonal stimulation from vertical wells (e.g. Howard and Fast, 1970). It entails the use of fewer or smaller perforation holes in order to increase pressure across the perforations, especially for the outer and/or heel-ward clusters of the stag. In this way the technique promotes fluid/proppant injection to the central/toe-ward clusters. Its advantage is that it is operationally simple to execute. Model predictions demonstrate its potential to promote uniform fluid/proppant distributions (Lecampion and Desroches, 2015; Daneshy, 2015). However, Lecampion et al. (2015) show that success is sensitive to the details of the design. Hence, it is unlikely that a rough guess at perforation cluster design for limited entry will be successful and so model-driven design is required. But, more problematically, this sensitivity to details shows a possible lack of robustness to perturbations from the designed entry losses, for example due to unexpected near wellbore fracture tortuosity as well as plugging and/or erosion of perforation holes as the stimulation progresses.

2. Diverting Agents: Diverting Agents are additives that are intended to collect at the entry of the fracture that are taking the most fluid, eventually blocking them so that fluid is diverted to other clusters. They are designed to naturally degrade and/or dislodge and flow out of the well during flow back and/or production and, like limited entry methods, their origins like in multi-zonal stimulation from vertical wells (Gallus and Pye, 1972). Field trials show that diversion is response to pumping a diverter is incomplete, yet often deemed sufficient to be practically effective. For example, Potapenko et al. (2009) show that the spatial distribution of microseismicity shifts along a horizontal well in the Barnett Shale after a diverting agent is pumped. Microseismicity continues to be generated from the region that was apparently the focus of stimulation before the diverter was pumped so diversion is apparently not complete although it is certainly demonstrable. Similar conclusions can be drawn from a case study of 3 wells in the Eagle Ford Shale, where the monitoring included not only microseismicity but also unique radioactive tracers that were pumped before and after diverting agents were introduced (Viswanathan et al., 2014). Again these results show that not every diverter pill results in measureable diversion and the diversion, when effective, is not complete. In the absence of advanced monitoring, diversion is usually said to have been successful when the well head pressure rises after injection of the diversion pill, and another pressure peak/drop ("breakdown") is observed, although obviously this does not ensure uniformity of the treatment.

3. Log-Driven Perforation Cluster Placement: This approach employs (typically) multipole sonic (wavespeed) data, interpreted in order to estimate the distribution of stress along the wellbore (Slocombe et al., 2013). Perforation cluster locations are chosen so as to minimize variation of stress among the clusters within each stage. A major field trial in the Eagle Ford Shale demonstrated that this approach decreases the variation of stress among the clusters within each stage from upwards of 1000 psi to a couple hundred psi. In so doing, the percentage of non-producing clusters is approximately cut in half relative to the control group of wells wherein perforation clusters are uniformly-spaced without regard for stress or other reservoir properties. Slocombe et al. (2013) do not, however, report the impact on productivity of the wells. On the other hand, Lim et al. (2014) report production impacts relative to a control group for 4 wells in the Marcellus Shale. The log-driven placement cases produced over $20 \%$ more gas over their first 400 days than the control group. However, when production is normalized for differences in number of perforation clusters among the wells, impact on production is only in the range of a 5-10\% increase. Nonetheless, the potential is clear. However, a major 

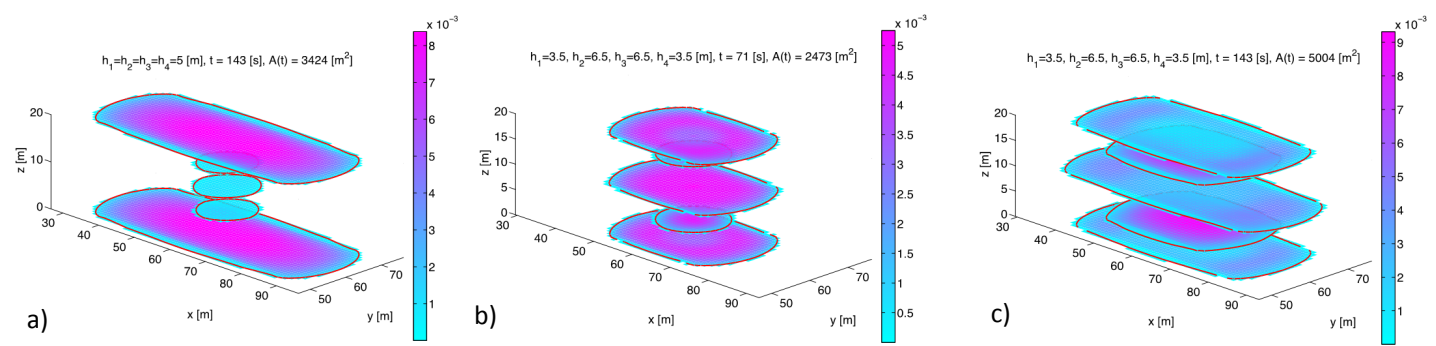

Figure 11. Planar 3D model results illustrating stress shadow and "interference" fracturing (from Peirce and Bunger, ress, , with permission). a) Stress shadow suppression of central fracture for 5 uniformalyspaced HFs, b-c) Improved uniformity obtained by moving entry point for HFs 2 and 4 to be closer to HFs 1 and 5. Here (b) illustrates how this change encourages growth of HF 3 (central HF) early in the growth, after which (c) illustrates the transition to injection preferentially going to HFs 2 and 4 . Note the $z$ axis in these plots is the direction of the horizontal well.

drawback of the approach is cost; execution requires logging and interpretation that is almost never carried out otherwise for onshore, low permeability gas/oil wells.

4. "Interference Fracturing": This so-far model-based approach essentially seeks to balance the impact of stress shadow on each fracture by varying the spacing between HFs. It is therefore a corollary of log-based selective of cluster location, but instead of focusing on pre-existing stress it focuses on HF induced stress. For a five cluster per stage example, Peirce and Bunger (ress) show that stress shadow can be balanced by moving the second and fourth clusters closer to the first and fifth clusters, respectively (Figure 11b). In this way, stress shadow is increased on clusters 1 and 5 and decreased on cluster 3 , leading to more balanced distribution of fluid relative to uniform spacing. Interestingly, as some point during injection clusters 2 and 5 begin taking fluid preferentially to 1,3 , and 5 so that a relatively uniform final distribution of fractures is achieved (Figure 11c).

5. Promoting Growth in Viscosity Dominated Regime: Analytical and numerical models agree that growth of multiple HFs (planar as opposed to network-like) is more stable for viscositydominated HFs (Bunger, 2013; Bunger and Peirce, 2014; Lecampion et al., 2015). While still untested at lab or field scale, one implication is that water-driven HFs may be more evenly distributed if the water injection is preceded by a high viscosity gel pad to promote initiation and growth from all perforation clusters. 


\subsection{Laboratory Investigations}

Simultaneous growth of multiple hydraulic fractures poses a significant challenge for laboratory experimentation. The problem is mainly associated with initiation of multiple hydraulic fractures at laboratory length and time scales. Whether in the laboratory or the field, the first to initiate among several possible entry points will correspond to lowest stress or the weakest rock. Subsequent intitiation is hypothesized to rely upon delayed rock failure (Bunger and $\mathrm{Lu}$, ress) or the continued increase in pressure that can occur following HF initiation (Bunger et al., 2010; Abbas and Lecampion, 2013). At laboratory scale, the experimental duration is often too short for the former mechanism and the fluid viscosity too small for the latter. Furthermore, even in laboratory experiments where there is evidence of multiple HF initiation, all but one of the initiated HFs stops growing so that most of the growth is concentrated in just a single HF (El-Rabaa, 1989).

Nonetheless, after many documented challenges, Crosby (1999) (see also Crosby et al., 2002) was able to obtain two simultaneously growing hydraulic fractures in concrete blocks. One of these initially-parallel HFs curved towards and eventually intersected the other, a type of attractive curving that is predicted by models (e.g. Bunger et al., 2012; Sesetty and Ghassemi, 2013; Daneshy, 2015, prediction 1, above). This attractive curving is also observed in laboratory experiments for sequential HF growth in crystalline rock by Bunger et al. (2011), who show that the curving is suppressed by increasing the minimum stress, as predicted by the simulations of Bunger et al. (2012) (As an aside, the simulations indicate the curving can also be reduced but not suppressed by increasing the deviatoric stress).

\subsection{Field Evidence}

In spite of the goal of uniform stimulation, field evidence indicates that stimulation is most often far from uniform. For example, distributed acoustic sensing (DAS) using fiber optic sensors along a horizontal well in a shale reservoir shows good initiation from all 9-10 clusters in each stage of this study. However, as the treatment goes on, one cluster dominates, taking in total 30\%-70\% of the fluid and proppant that is injected (Sookprasong et al., 2014). Similarly, growth from multiple perforation clusters but with dominance of one cluster can be inferred from microseismic data from the Barnett Shale (Daniels et al., 2007).

Concurring evidence of non-uniform stimulation is provided by distribution production as measured by wireline production logs. Analyzing over 100 production logs from horizontal wells in a variety of plays, Cipolla et al. (2010) show that 30\%-40\% of the perforation clusters are nonproductive, while in 4 examples, the top producing cluster (out of about 30 in all cases) produces $15 \%-45 \%$ of the total gas generated by the well. In another example, which is more detailed but for only a single well, Bunger and Cardella (2015) present statistical analysis of a production $\log$ from a Marcellus Shale gas well. This data shows contributions from all of the 105 perforation clusters. Besides apparently random variation this is presumably attributable to reservoir variability, there is a demonstrable bias of production to clusters at the heel end of a given stage. This observation suggests a bias in fluid/proppant delivery to the heel cluster relative to others. Hence, the previous-stage stress shadow, in the past inferred from increasing Instantaneous Shut in Pressure (ISIP) from toe to heel in wells (Vermylen and Zoback, 2011; Manchanda et al., 2014) as well as changes in correlation between ISIP and moment magnitude of microseismicity (Vermylen and Zoback, 2011), also makes HFs grow preferentially from heel-ward clusters where the stress shadow is smaller. Besides this heel-ward bias, there is a measureable bias also to outer clusters (both heel-ward and toe-ward) relative to central clusters in each stage (consistent with model prediction 1 , above).

Besides non-uniformity of stimulation, the impact of stress shadow on HF paths at field scale is also of interest. Certainly there is an intuitive notion that HF paths should be impacted by the region of elevated stress induced by the previous stage. Indeed pressure increases below the plug/packer that isolates the current fracturing stage from previous stages have been presented and interpreted as evidence for HF deflection/re-orientation that resulted in stress interaction and/or intersection between the growing HF(s) and HFs from previous stage(s) (Daneshy, 2014). Hence the deflection/re-orientation hypothesis has some support from field data. However, as valuable as the data is, the evidence is indirect, without a sense of the proportion of wells that exhibit this below plug/packer pressurization, and the interpretation is dependent on an underlying assumption 
that there is no leakage along the wellbore through the cement nor is there any fluid bypass of the plug/packer.

Moving beyond indirect evidence, some direct observations also support the hypothesis of HF curving while also pointing to a caveat that HF curving or re-orientation is not always obtained, even for very closely spaced HFs. Some relevant evidence comes from a multiple sequential fracturing experiment from a vertical well carried out by Oak Ridge National Lab (de Laguna et al., 1968). In this investigation, HF paths are inferred from intersections with offset wells and, as pointed out in the interpretation from Bunger et al. (2012), two of the five fractures in one component of this trial appear to have been deflected away from previous fractures. This behavior is consistent with simulations (Bunger et al., 2012). Counter-intuitively, the HFs that curved had a larger spacing between them than those that did not; this, too, is consistent with the same, counter-intuitive model prediction associated with the fact that principal stress orientations are nearly fracture-parallel both very close to and very far from a previously-placed HF (Bunger et al., 2012). A lack of curving, again consistent with model predictions, is also demonstrated in mine through data (Bunger et al., 2011). Unfortunately, definitive evidence of HF deflection, or lack thereof, has proven challenging to obtain in shale reservoirs themselves that are subjected to very closely spaced hydraulic fracturing. Hence, the importance of HF deflection at that scale and under actual reservoir conditions remains unknown.

\subsection{State of Knowledge}

In summary, the field-tested and model-suggested approaches to promote multiple fracture growth either increase energy dissipation associated with fluid flow (see discussion of Bunger et al., 2014), balance stresses resisting HF growth, or divert the fluid at the wellbore. But, in spite of the lack of conflict among the approaches, to date there is no known experience combing them in a given treatment. For example, log-based locations that minimize stress differences, injection of high viscosity pads, and limited entry are probably most important for initiation and early stages of growth. And they certainly can in principle be used together to increase their collective robustness. As the treatment continues, the induced stress shadow increases and hence interference fracturing, which balances the induced stress shadow among the fractures, could be important to ensure continued growth. Simulations show, however, that eventually influx to some fractures diminishes as interference fracturing growth. At this point, introduction of a diverter would promote influx to these otherwise suppressed fracture. Taken together, hybrid approaches that leverage multiple methods for promoting simultaneous HF growth have significant potential to improve the effectiveness of multistage, multi-cluster horizontal well completions.

There is one important footnote to the subject of generating multiple, simultaneously-growing hydraulic fractures. An obvious alternative is to avoid the need to simultaneously generate hydraulic fractures by individually isolating the zones that are intended to be stimulated. These "pinpoint" or "single-entry" methods exist; indeed, like limited entry methods, they have their roots in stimulation of multiple zones from vertical wells (e.g. Houser and Hernandez, 2009). These single entry methods, when applied to multi-stage stimulation from horizontal wells, have distinct advantages and, in a recent case study carried out in the Granite Wash, Anadarko Basin, Texas, have been shown to drastically reduce production decline and approximately double the wells Estimated Ultimate Recovery (EUR) (Maxwell et al., 2013). The main drawback is the cost of these systems. Hence, concurrent with the efforts to improve simultaneous generation of hydraulic fractures from multiple entry points are concerted efforts to develop increasingly-economical single-entry stimulation systems.

\section{CONCLUSIONS}

This review has focused on height growth, near wellbore tortuosity, network HF growth in naturally fractured reservoirs, and simultaneous growth of multiple HFs. When examining all of these together, we see the importance of certain issues crosscutting multiple topics. For example, high viscosity and high injection rate promote height growth through increasing the net pressure, diminish near wellbore tortuosity, suppress complex network-like growth geometry, and promote simultaneous growth of HFs from multiple entry points. Hence, the fluid choice and pumping schedule impacts in a multiplicity of ways. 
Similarly, the in situ stresses impact multiple aspects of HF growth. For starters, height growth is mainly controlled by the difference between the minimum stress in the reservoir and neighboring formations. At the same time, increasing the difference between the two horizontal principal stresses promotes simpler fracture geometry, both from the perspective of diminishing fracture tortuosity associated with initiation and promoting localized over network-like growth.

Of the monitoring methods, microseismic monitoring is shown to give insights that crosscut multiple areas of interest. It is used to estimate the extent of height growth, to ascertain the effectiveness of diverting agents for promiting multiple HF growth, and, in some cases, to discern growth of multiple HFs and/or network versus localized growth. However, the location uncertainty (order of tens of feet) limits resolution so that microseismicity is unable to distinguish network from localized growth, or to discern growth from multiple entry points, when the entry points are separated by tens of feet.

The future advances in each of these areas also possess some common themes. Firstly, modeling insights in all areas are limited by the open challenges associated with 3D modeling that maintains the appropriate coupling among fluid flow, rock deformation, and rock breakage. Fully coupled, fully 3D HF simulation would enable unprecendented insight into the role of layering and weak interfaces in HF height growth, the controlling factors in near wellbore fracture tortuosity, and the impact of nature fractures and hard/soft or high/low permeability inclusions on HF paths and possible formation of fracture networks.

Development of coupled 3D simulators, however, not only generates insights but also highlights a second area for future advances. As modeling pushes forward, the critical limitation increasingly becomes characterization. Height growth will be controlled by potentially poorly constrained in situ stresses and mechanical details of the lithological boundaries that are unresolvable with current measurements. Near wellbore tortuosity is almost certainly controlled by heterogeneity at a currently unresolvable scale and/or at a depth that, while still in the near-wellbore region from the perspective of the HF, is out of the reach of current well logging technology. Network growth is dependent not only on the density, orientation, and mechanical properties of natural fracture sets, but also on the extent of the natural fractures and other heterogeneities. These details are all beyond the reach of the state of the art in characterization and highlight the need for concerted research efforts. In the absence of these advances, the problem will remain intractable due to limited data even with unbounded growth in simulation capability.

Finally, all areas are limited by the resolution of the available monitoring methods. Profound gains would be enabled with, for example, the ability to resolve millimeter-scale detail in the near wellbore region and reducing the location uncertainty associated with microseismic monitoring by one order of magnitude.

\section{ACKNOWLEDGEMENTS}

The authors wish to thank Egor Dontsov and Anthony Peirce for providing unpublished data and Robert Hurt for pointing us to several relevant sets of published field data regarding stress shadow and fracture re-orientation. Numerous discussions with Jean Desroches on near-wellbore effects and HF in general are also gratefully acknowledged. 


\section{Bibliography}

Abass, H., M. van Domelen, and W. El-Rabaa (1990). Experimental observations of hydraulic fracture propagation through coal blocks. In SPE Eastern Regional Meeting, Columbus, Ohio. SPE 21289.

Abass, H. H., S. Hedayati, and D. L. Meadows (1996). Nonplanar fracture propagation from a horizontal wellbore: Experimental study. SPE Production \& Facilities 11(3), 133-137.

Abass, H. H., M. Y. Soliman, A. M. Tahini, J. Surjaatmadja, D. L. Meadows, and L. Sierra (2009, Oct 4-7). Oriented fracturing: A new technique to hydraulically fracture an openhole horizontal well. In Proceedings SPE Annual Technical Conference and Exhibition, New Orleans, LA, USA. SPE 124483.

Abbas, S., E. Gordeliy, A. P. Peirce, B. Lecampion, D. Chuprakov, and R. Prioul (2014). Limited height growth and reduced opening of hydraulic fractures due to fractureoffsets: An XFEM application. In SPE Hydraulic Fracturing Technology Conference, The Woodlands, Texas. SPE 168622.

Abbas, S. and B. Lecampion (2013). Initiation and breakdown of an axisymmetric hydraulic fracture transverse to a horizontal wellbore. In A. P. Bunger, J. McLennan, and R. G. Jeffrey (Eds.), Effective and Sustainable Hydraulic Fracturing, Chapter 19. Rijeka, Croatia: Intech.

Abou-Sayed, A., R. Clifton, R. Dougherty, and R. Morales (1984, 13-15 May). Evaluation of the influence of in-situ reservoir conditions on the geometry of hydraulic fractures using a 3-d simulator: Part 2-case studies. In SPE Unconventional Gas Recovery Symposium, Pittsburgh, PA, USA. Society of Petroleum Engineers. SPE 12878.

Adachi, J., E. Siebrits, A. Peirce, and J. Desroches (2007). Computer simulation of hydraulic fractures. Int. J. Rock Mech. Min. Sci. 44, 739-757.

Advani, S. H., T. S. Lee, and J. Lee (1990). Three-dimensional modeling of hydraulic fractures in layered media: part ifinite element formulations. Journal of Energy Resources Technology 112(1), 1-9.

Alekseenko, O. P., D. I. Potapenko, S. G. Cherny, D. V. Esipov, D. S. Kuranakov, and V. N. Lapin (2012, 6-8 February). 3-d modeling of fracture initiation from perforated non-cemented wellbore. In SPE Hydraulic Fracturing Technology Conference, The Woodlands, Texas, USA. Society of Petroleum Engineers. SPE 151585.

Aud, W., T. Wright, C. Cipolla, and J. Harkrider (1994, 25-28 September). The effect of viscosity on near-wellbore tortuosity and premature screenouts. In SPE Annual Technical Conference and Exhibition, New Orleans, Louisiana, USA. SPE 28492.

Bahorich, B., J. E. Olson, and J. Holder (2012). Examining the effect of cemented natural fractures on hydraulic fracture propagation in hydrostone block experiments. In SPE Annual Technical Conference and Exhibition, San Antonio, Texas. SPE 160197.

Behrmann, L. and K. Nolte (1999). Perforating requirements for fracture stimulations. SPE Drilling \& Completion 14(4). SPE 59480.

Behrmann, L. A. and J. L. Elbel (1991). Effect of perforations on fracture initiation. Journal of Petroleum Technology 43(5), 608-615. SPE 20661.

Ben Naceur, K. and E. Touboul (1990). Mechanisms controlling fracture-height growth in layered media. SPE Production Engineering 5(2), 142-150.

Beugelsdijk, L., C. J. de Pater, and K. Sato (2000, 25-26 April). Experimental hydraulic fracture propagation in a multi-fractured medium. In SPE Asia Pacific Conference on Integrated Modelling for Asset Management, Yokohama, Japan. SPE 59419. 
Blair, S. C., R. K. Thorpe, and F. E. Heuze (1990). Propagation of fluid-driven fractures in jointed rock.: Part 2physical tests on blocks with an interface or lens. 27(4), 255-268.

Blanton, T. L. (1982). An experimental study of interaction between hydraulic fractures and preexisting fractures. In Proc. SPE/DOE Unconventional Gas Recovery Symposium, Pittsburgh, PA, USA, pp. 613-627. SPE 10847.

Bunger, A. P. (2013). Analysis of the power input needed to propagate multiple hydraulic fractures. Int. J. Solids Struct. 50, 1538-1549.

Bunger, A. P. and D. J. Cardella (2015). Spatial distribution of production in a marcellus shale well: Evidence for hydraulic fracture stress interaction. 113, 162-166.

Bunger, A. P., R. G. Jeffrey, and X. Zhang (2011, June 26-29). Experimental investigation of the interaction among closely spaced hydraulic fractures. In Proceedings 45th U.S. Rock Mechanics Symposium, San Francisco, CA, USA. Paper No. 11-318.

Bunger, A. P., R. G. Jeffrey, and X. Zhang (2014). Constraints on simultaneous growth of hydraulic fractures from multiple perforation clusters in horizontal wells. Soc. Pet. Eng. J. 19(04), 608-620.

Bunger, A. P., J. Kear, R. G. Jeffrey, R. Prioul, and D. Chuprakov (2015, May 10-13). Laboratory investigation of hydraulic fracture growth through weak discontinuities with active ultrasound monitoring. In Proceedings 13th International Society for Rock Mechanics (ISRM) Congress, Montreal, Quebec, Canada.

Bunger, A. P., A. Lakirouhani, and E. Detournay (2010, August 25-27). Modelling the effect of injection system compressibility and viscous fluid flow on hydraulic fracture breakdown pressure. In Proceedings 5th International Symposium on In-situ Rock Stress, Beijing, P.R. China.

Bunger, A. P. and G. Lu (In Press). Time-dependent initiation of multiple hydraulic fractures in a formation with varying stresses. Soc. Pet. Eng. J..

Bunger, A. P. and A. P. Peirce (2014, June 21-23). Numerical simulation of simultaneous growth of multiple interacting hydraulic fractures from horizontal wells. In Proceedings ASCE Shale Energy Engineering Conference, Pittsburgh, PA, USA.

Bunger, A. P., X. Zhang, and R. G. Jeffrey (2012). Parameters effecting the interaction among closely spaced hydraulic fractures. Soc. Pet. Eng. J. 17(1), 292-306.

Burghardt, J., J. Desroches, B. Lecampion, S. Stanchits, A. Surdi, N. Whitney, and M. Houston (2015, May 10-13). Laboratory study of the effect of well orientation, completion design and rock fabric on near-wellbore hydraulic fracture geometry in shales. In $13^{\text {th }}$ ISRM International Symposium on Rock Mechanics, Montreal, Quebec, Canada.

Carter, B., J. Desroches, A. Ingraffea, and P. Wawrzynek (2000). Modeling in geomechanics, Volume 200, Chapter Simulating fully 3D hydraulic fracturing, pp. 525-557. Wiley Chichester.

Carter, B. J., X. Weng, J. Desroches, and A. Ingraffea (1999). Hydraulic fracture reorientation: Influence of 3d geometry. In Hydraulic Fracturing Workshop, 37th US Rock Mechanics Symposium, Vail, Co.

Ceccarelli, R., G. Pace, A. Casero, A. Ciuca, and M. Tambini (2010). Perforating for fracturing: Theory vs. field experiences. In SPE International Symposium and Exhibition on Formation Damage Control. SPE 128270.

Chang, F., K. Bartko, S. Dyer, G. Aidagulov, R. Suarez-Rivera, and J. Lund (2014, 4-6 February). Multiple fracture initiation in openhole without mechanical isolation: First step to fulfill an ambition. In SPE Hydraulic Fracturing Technology Conference, The Woodlands, Texas, USA. SPE 168638.

Cherny, S., D. Chirkov, V. Lapin, A. Muranov, D. Bannikov, M. Miller, D. Willberg, O. Medvedev, and O. Alekseenko (2009). Two-dimensional modeling of the near-wellbore fracture tortuosity effect. International Journal of Rock Mechanics and Mining Sciences 46(6), 992-1000.

Chipperfield, S. T., G. Roberts, W. K. Miller II, and R. Vandersypen (2000, 3-5 April). Gel slugs: A near-wellbore pressure-loss remediation technique for propped fracturing. In SPE/CERI Gas Technology Symposium, Calgary, Alberta, Canada. SPE 59777.

Chuprakov, D., O. Melchaeva, and R. Prioul (2013). Hydraulic fracture propagation across a weak discontinuity controlled by fluid injection. In A. P. Bunger, J. McLennan, and R. G. Jeffrey (Eds.), Effective and Sustainable Hydraulic Fracturing, Chapter 8. Rijeka, Croatia: Intech.

Chuprakov, D., O. Melchaeva, and R. Prioul (2014). Injection-sensitive mechanics of hydraulic fracture interaction with discontinuities. Rock Mech. Rock Eng.. doi:10.1007/s00603-0140596-7. 
Chuprakov, D. A. and R. Prioul (2015). Hydraulic fracture height containment by weak horizontal interfaces. In SPE Hydraulic Fracturing Technology Conference, The Woodlands, Texas. SPE 173337.

Cipolla, C., X. Weng, H. Onda, T. Nadaraja, U. Ganguly, and R. Malpani (2011, 30 October-2 November). New algorithms and integrated workflow for tight gas and shale completions. In Proceedings SPE Annual Technology Conference and Exhibition, Denver, Colorado, USA. SPE 146872.

Cipolla, C. L., M. G. Mack, and S. C. Maxwell (2010). Reducing exploration and appraisal risk in low permeability reservoirs using microseismic fracture mapping - part 2. In SPE Latin American and Caribbean Petroleum Engineering Conference, Lima, Peru. SPE 138103.

Cleary, M., D. Johnson, H. Kogsbøll, K. Owens, K. Perry, C. De Pater, A. Stachel, H. Schmidt, and M. Tambini (1993, 26-28 April). Field implementation of proppant slugs to avoid premature screen-out of hydraulic fractures with adequate proppant concentration. In Low permeability reservoirs symposium, Denver, Colorado, USA. Society of Petroleum Engineers. SPE 25892.

Crosby, D. G. (1999). The Initiation and Propagation of, and Interaction Between, Hydraulic Fractures from Horizontal Wellbores. Ph. D. thesis, University of New South Wales, Australia.

Crosby, D. G., M. M. Rahman, M. K. Rahman, and S. S. Rahman (2002). Single and multiple transverse fracture initiation from horizontal wells. Journal of Petroleum Science and Engineering 35(3-4), 191 - 204.

Daneshy, A. (1973a, October). Experimental investigation of hydraulic fracturing through perforations. J. Pet. Tech. 25. SPE 4333.

Daneshy, A. (1973b, April). A study of inclined hydraulic fractures. SPE Journal, 61-68.

Daneshy, A. (1978a, January). Numerical solution of sand transport in hydraulic fracturing. $J$. Pet. Tech., 132-140. (SPE 5636)pdf.

Daneshy, A. (2009, 19-21 January). Factors controlling the vertical growth of hydraulic fractures. In SPE Hydraulic Fracturing Technology Conference, The Woodlands, Texas, USA. SPE 118789.

Daneshy, A. A. (1978b). Hydraulic fracture propagation in layered formations. Soc. Pet. Eng. J. 18(01), 33-41. SPE 6088.

Daneshy, A. A. (2014, 27-29 October). Fracture shadowing: Theory, applications and implications. In Proceedings SPE Annual Technical Conference and Exhibition, Amsterdam, The Netherlands. SPE 170611.

Daneshy, A. A. (2015). Dynamic interaction within multiple limited entry fractures in horizontal wells: Theory, implications, and field verification. In SPE Hydraulic Fracturing Technology Conference, The Woodlands, Texas. SPE 173344.

Daniels, J., G. Waters, J. LeCalvez, J. Lassek, and D. Bentley (2007, October 12-14). Contacting more of the Barnett Shale through and integration of real-time microseismic monitoring, petrophysics, and hydraulic fracture design. In Proceedings SPE Annual Technical Conference and Exhibition, Anaheim, California, USA. SPE 110562.

Davies, R. J., S. A. Mathias, J. Moss, S. Hustoft, and L. Newport (2012). Hydraulic fractures: How far can they go? Marine and Petroleum Geology 37(1), 1-6.

de Laguna, W., E. G. Struxness, T. Tamara, W. C. McClain, H. O. Weeren, and R. C. Sexton (1968). Engineering development of hydraulic fracturing as a method for permanent disposal of radioactive wastes. Technical Report ORNL-4259, Oak Ridge National Laboratory, Oak Ridge, Tennessee, USA. www.ornl.gov/info/reports/1968/3445605101608.pdf.

de Pater, C. J. and L. J. L. Beugelsdijk (2005). Experiments and numerical simulation of hydraulic fracturing in naturally fractured rock. In Proceedings 40th US Symposium on Rock Mechanics, Anchorage, Alaska, pp. June 25-29.

de Pater, C. J. and Y. Dong (2009, January 19-21). Fracture containment in soft sands by permeability or strength contrasts. In Proceedings SPE Hydraulic Fracturing Technology Conference and Exhibition, The Woodlands, Texas, USA. SPE 119634.

Desroches, J., B. Lecampion, H. Ramakrishnan, R. Prioul, and E. Brown (2014, Sept. 30 - Oct. 2). Benefits of controlled hydraulic fracture placement: Theory and field experiment. In SPE/CSUR Unconventional Resources Conference, Calgary, Alberta, Canada. SPE 171667.

Detournay, E. and E. Carbonell (1997, August). Fracture mechanics analysis of the breakdown process in minifracture or leakoff test. SPE Production \& Facilities, 195-199. 
Diamond, W. P. and D. C. Oyler (1987). Effects of stimulation treatments on coalbeds and surrounding strata. Technical Report Report of Investigations 9083, United States Bureau of Mines.

Doe, T. and G. Boyce (1989). Orientation of hydraulic fractures in salt under hydrostatic and non-hydrostatic stresses. 26(6), 605-611.

Dohmen, T., J. Zhang, and J. P. Blangy (2014, 27-29 October). Measurement and analysis of 3D stress shadowing related to the spacing of hydraulic fracturing in unconventional reservoirs. In Proceedings SPE Annual Technical Conference and Exhibition, Amsterdam, The Netherlands. SPE 170924.

Dohmen, T., J. Zhang, C. Li, J. P. Blangy, K. M. Simon, D. N. Valleau, J. D. Eules, S. Morton, and S. Checkles (2013, 30 September - 2 October). A new surveillance method for delineation of depletion using microseismic, and its application to development of unconventional reservoirs. In Proceedings SPE Annual Technical Conference and Exhibition, New Orleans, LA, USA. SPE 166274.

Dontsov, E. V. and A. P. Peirce (2015). An enhanced pseudo-3d model for hydraulic fracturing accounting for viscous height growth, non-local elasticity, and lateral toughness. Eng. Fracture. Mech. 142, 116-139.

Economides, M. J. and K. G. Nolte (2000). Reservoir stimulation. Schlumberger: John Wiley \& Sons.

El-Rabaa, W. (1987). Hydraulic fracture propagation in the presence of stress variation. In SPE Annual Technical Conference and Exhibition, Dallas, Texas. SPE 16898.

El-Rabaa, W. (1989, Oct 8-11). Experimental study of hydraulic fracture geometry initiated from horizontal wells. In Proceedings SPE Annual Technical Conference and Exhibition, San Antonio, TX, USA. SPE 19720.

Elder, C. H. (1977). Effects of hydraulic stimulation on coalbeds and assciated strata. Technical Report Report of Investigations 8260, United States Bureau of Mines.

EPA (2004). Evaluation of impacts to underground sources of drinking water by hydraulic fracturing of coalbed methane reservoirs. Technical Report EPA 816-R-04-003, United States Environmental Protection Agency, Washington, D.C.

Fallahzadeh, S. H., V. Rasouli, and M. Sarmadivaleh (2014). An investigation of hydraulic fracturing initiation and near-wellbore propagation from perforated boreholes in tight formations. Rock Mechanics and Rock Engineering.

Fast, R., A. Murer, and R. Timmer (1994). Description and analysis of cored hydraulic fractures, Lost Hills Field, Kern County, California . SPE Production \& Facilities 9(02), $107-114$. SPE 24853.

Fisher, K. and N. Warpinski (2012). Hydraulic fracture height growth: Real data. SPE Production and Operations 27(1), 8-19. SPE 145949.

Fisher, M., C. Wright, B. Davidson, A. Goodwin, E. Fielder, W. Buckler, and N. Steinsberger (2002). Integrating fracture mapping technologies to optimize stimulations in the Barnett Shale. In SPE Annual Technical Conference and Exhibition, San Antonio, Texas. SPE 77441.

Fisher, M. K., J. R. Heinze, C. D. Harris, B. M. Davidson, C. A. Wright, and K. P. Dunn (2004, September 29-29). Optimizing horizontal completion techniques in the barnett shale using microseismic fracture mapping. In Proceedings SPE Annual Technology Conference and Exhibition, Houston, Texas, USA. SPE 90051.

Fu, W., B. C. Ames, A. P. Bunger, and A. A. Savitski (2015, 28 June - 1 July). An experimental study on interaction between hydraulic fractures and partially-cemented natural fractures. In Proceedings 49th U.S. Rock Mechanics Symposium, San Francisco, CA, USA. Paper No. 15132.

Gallus, J. P. and D. S. Pye (1972). Fluid diversion to improve well stimulation. In Joint AIMEMMIJ Meeting, Tokyo, Japan. SPE 3811.

Geertsma, J. and F. de Klerk (1969). A rapid method of predicting width and extent of hydraulic induced fractures. J. Pet. Tech. 246, 1571-1581. (SPE 2458).

Germanovich, L. N., L. M. Ring, D. K. Astakhov, J. Shlyopobersky, and M. J. Mayerhofer (1997). Hydraulic fracture with multiple segments II: Modeling. Int. J. Rock Mech. Min. Sci. 34(3-4), 472.

$\mathrm{Gu}, \mathrm{H}$. and E. Siebrits (2008). Effect of formation modulus contrast on hydraulic fracture height containment. SPE Production \& Operations 23(2), 170-176. 
Gu, H., E. Siebrits, and A. Sabourov (2008). Hydraulic fracture modeling with bedding plane interfacial slip. In SPE Eastern Regional/AAPG Eastern Section Joint Meeting, Pittsburgh, PA, USA. SPE 117445.

Gu, H., X. Weng, J. Lund, M. Mack, U. Ganguly, and R. Suarez-Rivera (2011, January 2426). Hydraulic fracture crossing natural fracture at non-orthogonal angles, A criterion, its validation and applications. In Proceedings SPE Hydraulic Fracturing Technology Conference and Exhibition, The Woodlands, Texas, USA. SPE 139984.

Gudmundsson, A. (2011). Deflection of dykes into sills at discontinuities and magma-chamber formation. Tectonophysics 500(1-4), 50-64.

Gudmundsson, A. and S. L. Brenner (2001). How hydrofractures become arrested. Terra Nova 13, 456-462.

Gudmundsson, A. and I. F. Loetveit (2005). Dyke emplacement in a layered and faulted rift zone. Journal of Volcanology and Geothermal Research 144(1-4), 311-327.

Gudmundsson, A., L. B. Marinoni, and J. Marti (1999). Injection and arrest of dykes: implications for volcanic hazards. Journal of Volcanology and Geothermal Research 88(1-2), 1-13.

Gulrajani, S. N. and J. Romero (1996, 22-24 October). Evaluation and modification of fracture treatments showing near-wellbore effects. In European Petroleum Conference, Milan, Italy. Society of Petroleum Engineers. SPE 36901.

Hainey, B., X. Weng, and R. Stoisits (1995, 22-25 October). Mitigation of multiple fractures from deviated wellbores. In SPE Annual Technical Conference and Exhibition, Dallas, Texas, USA. SPE 30482.

Hammack, R., S. Sharma, R. Capo, E. Zorn, H. Siriwardane, and W. Harbert (2013, 20-22 August). An evaluation of zonal isolation after hydraulic fracturing; results from horizontal Marcellus Shale gas wells at NETL's Greene County test site in Southwestern Pennsylvania. In SPE Eastern Regional Meeting, Pittsburgh, Pennsylvania, USA. SPE 165720.

Harmon, J. A. (1957, 1 January). The chemistry of fresh-water fracturing. In Drilling and Production Practice, New York, NY, USA. American Petroleum Institute. API-57-050.

Hassebroek, W. and A. Waters (1964). Advancements through 15 years of fracturing. J. Pet. Tech. 16(7), 760-764.

Houser, J. A. and R. A. Hernandez (2009). Pinpoint fracturing using a multiple-cutting process. In SPE Rocky Mountain Petroleum Technology Conference, Denver, Colorado. SPE 122949.

Howard, G. and C. Fast (Eds.) (1970). Volume 2. New York: Henry L. Doherty Fund, SPE.

Jackson, R. B., E. R. Lowry, A. Pickle, M. Kang, D. DiGiulio, and K. Zhao (2015). The depths of hydraulic fracturing and accompanying water use across the united states. Environmental Science and Technology 49(15), 8969-8976.

Jeffrey, R. and A. P. Bunger (2007, Jan 29-31). A detailed comparison of experimental and numerical data on hydraulic fracture height growth through stress contrasts. In Proceedings SPE Hydraulic Fracturing Technology Conference, College Station, Texas. SPE 106030.

Jeffrey, R. and A. P. Bunger (2009). A detailed comparison of experimental and numerical data on hydraulic fracture height growth through stress contrasts. Soc. Pet. Eng. J. 14(3), 413-422.

Jeffrey, R., Z. Chen, X. Zhang, A. Bunger, and K. Mills (2014). Measurement and analysis of full-scale hydraulic fracture initiation and fracture reorientation. In 48th US Rock Mechanics/Geomechanics Symposium. American Rock Mechanics Association.

Jeffrey, R. G., R. P. Brynes, and D. J. Ling (1992, May 18-21). An analysis of hydraulic fracture and mineback data for a treatment in the german creek coal seam. In Proceedings SPE Rocky Mountain Regional Meeting, Casper, Wyoming, USA. SPE 24362.

Jeffrey, R. G., A. P. Bunger, B. Lecampion, X. Zhang, Z. R. Chen, A. van As, D. Allison, W. D. Beer, J. W. Dudley, E. Siebrits, M. Thiercelin, and M. Mainguy (2009, October 4-7). Measuring hydraulic fracture growth in naturally fractured rock. In Proceedings SPE Annual Technical Conference and Exhibition, New Orleans, Louisiana, USA. SPE 124919.

Jeffrey, R. G., A. Settari, and N. P. Smith (1995, October 22-25). A comparison of hydraulic fracture field experiments, including mineback geometry data, with numerical fracture model simulations. In Proceedings SPE Annual Technical Conference and Exhibition, Dallas, Texas, USA. SPE 30508.

Johnson, E. and M. Cleary (1991). Implications of recent laboratory experimental results for hydraulic fractures. In Proc. Rock Mountains Regional Meeting and Low-Permeability Reservoirs Symposium, Denver, CO, pp. 413-428. SPE 21846. 
Kavanagh, J. L., T. Menand, and R. S. J. Sparks (2006). An experimental investigation of sill formation and propagation in layered elastic media. Earth and Planetary Science Letters 245(34), $799-813$.

Khristianovic, S. and Y. Zheltov (1955, June 6-15). Formation of vertical fractures by means of highly viscous fluids. In Proc. 4th World Petroleum Congress, Rome, pp. 579-586. Carlo Colombo, Rome.

King, G. E. (2010, September 19-22). Thirty years of gas shale fracturing: What have we learned? In Proceedings SPE Annual Technical Conference and Exhibition, Florence, Italy. SPE 133256.

Kogsbøll, H., M. Pitts, and K. Owens (1993, 7-10 September). Effects of tortuosity in fracture stimulation of horizontal wells- a case study of the dan field. In Offshore Europe, Aberdeen, United Kingdom. Soc. Petroleum Engineers. SPE 26796.

Kresse, O., X. Weng, D. Chuprakov, R. Prioul, and C. Cohen (2013). Effect of flow rate and viscosity on complex fracture development in UFM model. In A. Bunger, J. McLennan, and R. Jeffrey (Eds.), Effective and Sustainable Hydraulic Fracturing, Chapter 9. Rijeka, Croatia: Intech.

Kresse, O., X. Weng, H. Gu, and R. Wu (2013). Numerical modeling of hydraulic fractures interaction in complex naturally fractured formations. Rock Mechanics and Rock Engineering 46(3), $555-568$.

Kruger, P. and T. Yamaguchi (1993, January 26-28). Thermal drawdown analysis of the Hijiori HDR 90-day circulation test. In Proceedings 18th Stanford Workshop on Geothermal Reservoir Engineering, Stanford, CA, USA.

Lambert, S. W., M. A. Trevits, and P. F. Steidl (1980). Vertical borehole design and completion practices to remove methane gas from mineable coalbeds. Technical Report DOE/CMTC/TR80/2, United States Department of Energy.

Lecampion, B. and J. Desroches (2015). Simultaneous initiation and growth of multiple radial hydraulic fractures from a horizontal wellbore. J. Mech. Phys. Sol. 82, 235-258.

Lecampion, B., J. Desroches, R. Jeffrey, A. Bunger, and J. Burghardt (2015, May 10-13). Initiation versus breakdown pressure of transverse hydraulic fracture: theory and experiments. In $13^{\text {th }}$ ISRM International Symposium on Rock Mechanics, Montreal, Quebec, Canada.

Lecampion, B., J. Desroches, X. Weng, J. Burghardt, and J. E. Brown (2015). Can we engineer better multistage horizontal completions? Evidence of the importance of near-wellbore fracture geometry from theory, lab and field experiments. In SPE Hydraulic Fracturing Technology Conference, The Woodlands, Texas. SPE 173363.

$\mathrm{Li}, \mathrm{B}$. (2014). Natural fractures in unconventional shale reservoirs in US and their roles in well completion design and improving hydraulic fracturing stimulation efficiency and production. In SPE Annual Technical Conference and Exhibition, Amsterdam, The Netherlands. SPE 170934.

Li, Y., G. Liu, J. Li, L. Yu, T. Zhang, and J. Lu (2015). Improving fracture initiation predictions of a horizontal wellbore in laminated anisotropy shales. Journal of Natural Gas Science and Engineering 24, 390-399.

Lim, P. V., P. Goddard, J. Sink, and I. S. Abou-sayed (2014). Hydraulic fracturing: A Marcellus case study of an engineered staging completion based on rock properties. In SPE/CSUR Unconventional Resources Conference, Calgary, Alberta, Canada. SPE 171618.

Liu, S. and P. Valkó (2015, 3-5 February). An improved equilibrium-height model for predicting hydraulic fracture height migration in multi-layer formations. In SPE Hydraulic Fracturing Technology Conference, The Woodlands, Texas, USA. SPE 173335.

Llanos, E. M., R. G. Jeffrey, R. R. Hillis, and X. Zhang (2006). Study of the interaction between hydraulic fractures and geological discontinuities. In Rock mechanics in underground construction: ISRM International Symposium 2006 and 4th Asian Rock Mechanics Symposium, Singapore, pp. 378. World Scientific Pub Co Inc.

Mahrer, K. D. (1999). A review and perspective on far-field hydraulic fracture geometry studies. Journal of Petroleum Science and Engineering 24(1), 13-28.

Manchanda, R., M. M. Sharma, and S. Holzhauser (2014). Time-dependent fracture-interference effects in pad wells. SPE Production \& Operations 29(04), $274-287$.

Manrique, J. and A. Venkitaraman (2001, 30 September-3 October). Oriented fracturing - a practical technique for production optimization. In SPE Annual Technical Conference and Exhibition, New Orleans, Louisiana, USA. SPE 71652.

Maxwell, S., A. Pirogov, C. Bass, and L. Castro (2013). A comparison of proppant placement, well performance, and estimated ultimate recovery between horizontal wells completed with 
multi-cluster plug and perf and hydraulically activated frac ports in a tight gas reservoir. In SPE Hydraulic Fracturing Technology Conference, The Woodlands, Texas. SPE 163820.

Maxwell, S., T. Urbancic, N. Steinsberger, and R. Zinno (2002, 29 September-2 October). Microseismic imaging of hydraulic fracture complexity in the Barnett shale. In Proceedings SPE Annual Technical Conference and Exhibition, San Antonio, Texas, USA. SPE 77440.

Mayerhofer, M., M. Richardson, R. Walker Jr., D. Meehan, M. Oehler, and R. Browning Jr. (1997, October 5-8). Proppants? we don't need no proppants. In Proceedings SPE Annual Technical Conference and Exhibition, San Antonio, Texas, USA. SPE 38611.

Mayerhofer, M. J., N. A. Stegent, J. O. Barth, and K. M. Ryan (2011, 30 October - 2 November). Integrating fracture diagnostics and engineering data in the Marcellus Shale. In Proceedings SPE Annual Technical Conference and Exhibition, Denver, CO, USA. SPE 145463.

Mc Gowen, J., J. Gilbert, and E. Samari (2007, 29-31 January). Hydraulic fracturing down under. In SPE Hydraulic Fracturing Technology Conference, College Station, Texas, USA. SPE 106051.

McDaniel, B., D. McMechan, and N. Stegent (2001). Proper use of proppant slugs and viscous gel slugs can improve proppant placement during hydraulic fracturing applications. In SPE Annual Technical Conference and Exhibition. SPE 71661.

McDaniel, B. and J. Surjaatmadja (2009, 7-9 December). Using hydrajetting applications in horizontal completions to improve hydraulic fracturing stimulations and lower costs. In International Petroleum Technology Conference, Doha, Qatar. IPTC 13775.

Medelsohn, D. A. (1984a). A review of hydraulic fracture modelingII: 3D modeling and vertical growth in layered rock. ASME J. Energy Res. Tech. 106(4), 543-553.

Medelsohn, D. A. (1984b). A review of hydraulic fracture modelingpart I: General concepts, 2D models, motivation for 3D modeling. ASME J. Energy Res. Tech. 106(3), 369-376.

Meyer, B. and L. Bazan (2011, January 24-26). A discrete fracture network model for hydraulically induced fractures-theory, parametric and case studies. In Proceedings SPE Hydraulic Fracturing Technology Conference and Exhibition, The Woodlands, Texas, USA. SPE 140514.

Montgomery, C. T. and M. B. Smith (2010). Hydraulic fracturing: History of an enduring technology. J. Pet. Tech. 62(12), 26-40.

Nolte, K. G. (1993). Discussion of examination of a cored hydraulic fracture in a deep gas well. SPE Production \& Facilities 8(03), 159-164. SPE 26302.

Nolte, K. G. and M. B. Smith (1981). Interpretation of fracturing pressures. J. Pet. Tech. 33(9), $1767-1775$.

Nordgren, R. (1972). Propagation of vertical hydraulic fractures. J. Pet. Tech. 253, 306-314. (SPE 3009).

Northrop, D. A. and K.-H. Frohne (1990). The Multiwell Experiment - A field laboratory in tight gas sandstone reservoirs. J. Pet. Tech. 42(06), $772-779$. SPE 18286.

Olson, J. E. (2008, June 29-July 2). Multi-fracture propagation modeling: Applications to hydraulic fracturing in shales and tight gas sands. In Proceedings 42nd US Rock Mechanics Symposium, San Francisco, CA, USA. ARMA 08-327.

Olson, J. E., B. Bahorich, and J. Holder (2012). Examining hydraulic fracture: Natural fracture interaction in hydrostone block experiments. In SPE Hydraulic Fracturing Technology Conference, The Woodlands, Texas. SPE 152618.

Olson, J. E. and A. Dahi-Taleghani (2009, January 19-21). Modeling simultaneous growth of multiple hydraulic fractures and their interaction with natural fractures. In Proceedings SPE Hydraulic Fracturing Technology Conference and Exhibition, The Woodlands, Texas, USA. SPE 119739.

Owens, K., S. Andersen, and M. Economides (1992, 4-7 October). Fracturing pressures for horizontal wells. In SPE Annual Technical Conference and Exhibition, Washington, D.C., USA. SPE 24822.

Pandya, N. and O. Jaripatke (2014). Rate step-down analysis improves placement efficiency of stimulation treatments in unconventional resource play. In Unconventional Resources Technology Conference (URTeC), Denver, Co. URTeC 1943637.

Pearson, C., A. Bond, M. Eck, and J. Schmidt (1992, January). Results of stress-oriented and aligned perforating in fracturing deviated wells. J. Pet. Tech., 10-18. SPE 22836.

Peirce, A. and E. Detournay (2008). An implicit level set method for modeling hydraulically driven fractures. Computer Meth. Appl. Mech. Eng 197, 2858-2885. 
Peirce, A. P. and A. P. Bunger (In-Press). Interference fracturing: Non-uniform distributions of perforation clusters that promote simultaneous growth of multiple hydraulic fractures. Soc. Pet. Eng. J..

Perkins, T. and L. Kern (1961). Widths of hydraulic fractures. J. Pet. Tech., Trans. AIME 222, 937-949.

Pospisil, G., C. Carpenter, and C. Pearson (1995, 8-10 March). Impacts of oriented perforating on fracture stimulation treatments: Kuparuk river field, alaska. In SPE Western Regional Meeting, Bakersfield,Ca, USA. SPE 29645.

Potapenko, D. I., S. K. Tinkham, B. Lecerf, C. N. Fredd, M. L. Samuelson, M. R. Gillard, J. H. L. Calvez, and J. L. Daniels (2009). Barnett Shale refracture stimulations using a novel diversion technique. In SPE Hydraulic Fracturing Technology Conference, The Woodlands, Texas. SPE 119636.

Prats, M. and S. A. Maraven (1981). Effect of burial history on the subsurface horizontal stresses of formations having different material properties. Soc. Pet. Eng. J. 21(06), 658-662. SPE 9017.

Quinn, T. S. (1994). Experimental Analysis of Permeability Barriers to Hydraulic Fracture Propagation. Ph. D. thesis, Massachusetts Institute of Technology, Cambride, MA, USA.

Renshaw, C. E. and D. D. Pollard (1995). An experimentally verified criterion for propagation across unbounded frictional interfaces in brittle, linear elastic materials. Int. J. Rock Mech. Min. Sci. 32(3), 237-249.

Rivalta, E., M. Böttinger, and D. T (2005, jun). Buoyancy-driven fracture ascent: Experiments in layered gelatin. J. Volcanol. Geoth. Res. 144(1-4), 273-285.

Rivalta, E., B. Taisne, A. P. Bunger, and R. Katz (2015). A review of mechanical models of dike propagation: schools of thought, results and future directions. Tectonophysics 638, 1-42.

Roberts, G. A., S. T. Chipperfield, and W. K. Miller II (2000). The evolution of a high nearwellbore pressure loss treatment strategy for the australian cooper basin. In SPE Annual Technical Conference and Exhibition, Dallas, Tx, USA. SPE 63029.

Rogers, S., D. Elmo, and W. Dershowitz (2011, June 26-29). Understanding hydraulic fracture geometry and interactions in pre-conditioning through DFN and numerical modeling. San Francisco, CA, USA. Paper No. 11-439.

Roussel, N. P., R. Manchanda, and M. M. Sharma (2012, February 6-8). Implications of fracturing pressure data recorded during a horizontal completion on stage spacing design. In Proceedings SPE Hydraulic Fracturing Technology Conference, The Woodlands, Texas. SPE 152631.

Roussel, N. P. and M. M. Sharma (2010, Sept 19-22). Role of stress reorientation in the success of refracture treatments in tight gas sands. In Proceedings SPE Annual Technical Conference and Exhibition, Florence, Italy. SPE 134491.

Roussel, N. P. and M. M. Sharma (2011, May). Optimizing fracture spacing and sequencing in horizontal-well fracturing. SPE Production \& Operations 26(2), 173-184.

Saldungaray, P. M., T. T. Palisch, and R. Duenckel (2012, 20-22 March). Novel traceable proppant enables propped frac height measurement while reducing the environmental impact. In SPE/EAGE European Unconventional Resources Conference and Exhibition, Vienna, Austria. SPE 151696.

Sesetty, V. and A. Ghassemi (2013). Numerical simulation of sequential and simultaneous hydraulic fracturing. In A. P. Bunger, J. McLennan, and R. G. Jeffrey (Eds.), Effective and Sustainable Hydraulic Fracturing, Chapter 33. Rijeka, Croatia: Intech.

Settari, A. and M. P. Cleary (1984). Three-dimensional simulation of hydraulic fracturing. J. Pet. Tech. 36(8), 1177-1190.

Sheibani, F. and J. Olson (2013). Stress intensity factor determination for three-dimensional crack using the displacement discontinuity method with applications to hydraulic fracture height growth and non-planar propagation paths. In A. P. Bunger, J. McLennan, and R. G. Jeffrey (Eds.), Effective and Sustainable Hydraulic Fracturing, Chapter 37. Rijeka, Croatia: Intech.

Sherman, C., L. Aarons, J. Morris, S. Johnson, A. Savitski, and M. Geilikman (2015). Finite element modeling of curving hydraulic fractures and near- wellbore hydraulic fracture complexity. In 49th US Rock Mechanics Symposium / Geomechanics Symposium. ARMA 15-0530.

Simonson, E. R., A. S. Abou-Sayed, and R. J. Clifton (1978). Containment of massive hydraulic fractures. SPE Journal 18(1), 27-32.

Slocombe, R., A. Acock, K. Fisher, A. Viswanathan, C. Chadwick, R. Reischman, and E. Wigger (2013, 30 September - 2 October). Eagle Ford completion optimization using horizontal 
log data. In Proceedings SPE Annual Technology Conference and Exhibition, New Orleans, Lousiana, USA. SPE 166242.

Smith, M., A. Bale, L. Britt, H. Klein, E. Siebrits, and X. Dang (2001, 30 September-3 October). Layered modulus effects on fracture propagation, proppant placement, and fracture modeling. In SPE Annual Technical Conference and Exhibition, New Orleans, Louisiana, USA. Society of Petroleum Engineers. SPE 71654.

Soliman, M. Y., J. L. Hunt, and A. M. El-Raaba (1990). Fracturing aspects of horizontal wells. J. Pet. Tech. 42(8), 966-973.

Sookprasong, P. A., R. S. Hurt, and R. F. LaFollette (2014, Oct 27-29). Fiber optic DAS and DTS in multicluster, multistage horizontal well fracturing: Interpreting hydraulic fracture initiation and propagation through diagnostics. In Proceedings SPE Annual Technology Conference and Exhibition, Amsterdam, The Netherlands. SPE 170723.

Strain, H. (1962, December). Well-bore notching and hydraulic fracturing. Journal of Canadian Petroleum Technology 1. PETSOC-62-04-01.

Suarez-Rivera, R., J. Burghardt, S. Stanchits, E. Edelman, and A. Surdi (2013). Understanding the effect of rock fabric on fracture complexity for improving completion design and well performance. In International Petroleum Technology Conference, Beijing, China. IPTC 17018.

Surjaatmadja, J., H. H. Abass, and J. Brumley (1994, 7-10 November). Elimination of nearwellbore tortuosities by means of hydrojetting. In Asia Pacific Oil and Gas Conference, Melbourne, Australia. SPE 28761.

Teufel, L. W. and J. A. Clark (1984). Hydraulic fracture propagation in layered rock: Experimental studies of fracture containment. SPE Journal 24(1), 19-32.

Urbancic, T. and S. Maxwell (2002). Microseismic imaging of fracture behavior in naturally fractured reservoirs. In SPE/ISRM Rock Mechanics Conference, Irving, Texas. SPE 78229.

van As, A. and R. Jeffrey (2000). Caving induced by hydraulic fracturing at Northparkes Mines. In J. Girard, M. Liebman, C. Breeds, and T. Doe (Eds.), Pacific Rocks 2000 - Proc. 4th North American Rock Mechanics Symposium, Seatle, WA, pp. 353-360. Balkema.

van de Ketterij, R. G. (2001). Optimisation of the Near-wellbore geometry of hydraulic fractures propagating from cased perforated completions. Ph. D. thesis, TU Delft.

van de Ketterij, R. G. and C. J. de Pater (1997, 2-3 June). Experimental study on the impact of perforations on hydraulic fracture tortuosity. In SPE European Formation Damage Conference, The Hague, Netherlands. Society of Petroleum Engineers. SPE 38149.

van de Ketterij, R. G. and C. J. de Pater (1999). Impact of perforations on hydraulic fracture tortuosity. SPE Production \& Facilities 14(2), 131-138.

van Eekelen, H. A. M. (1982). Hydraulic fracture geometry: Fracture containment in layered formations. Soc. Pet. Eng. J. 22(3), 341-349.

Veeken, C., D. Davies, and J. Walters (1989, 6-8 March). Limited communication between hydraulic fracture and (deviated) wellbore. In Low Permeability Reservoirs Symposium, Denver, Co, USA. Soc. Petroleum Engineers. SPE 18982.

Vermylen, J. P. and M. D. Zoback (2011, January 24-26). Hydraulic fracturing, microseismic magnitudes, and stress evolution in the Barnett Shale, Texas, USA. In Proceedings SPE Hydraulic Fracturing Technology Conference and Exhibition, The Woodlands, Texas, USA. SPE 140507.

Viswanathan, A., H. Watkins, J. Reese, A. Corman, and B. V. Sinosic (2014). Sequenced fracture treatment diversion enhances horizontal well completions in the Eagle Ford Shale. In SPE/CSUR Unconventional Resources Conference, Calgary, Alberta, Canada. SPE 171660.

Warpinski, N., R. C. Kramm, J. R. Heinze, and C. K. Waltman (2005). Comparison of single-and dual-array microseismic mapping techniques in the Barnett Shale. In SPE Annual Technical Conference and Exhibition, Dallas, Texas. SPE 95568.

Warpinski, N., J. Lorenz, P. Branagan, F. Myal, and B. Gall (1993). Examination of a cored hydraulic fracture in a deep gas well. SPE Production \& Facilities 8(03), 150-158. SPE 22876.

Warpinski, N., R. Schmidt, and D. Northrop (1982). In-situ stresses: the predominant influence of hydraulic fracture containment. J. Pet. Tech. 34(3), 653-664. SPE 8932)pdf.

Warpinski, N., T. Wright, J. Uhl, B. Engler, P. Drozda, R. Peterson, and P. Branagan (1996). Microseismic monitoring of the B-Sand hydraulic fracture experiment at the DOE/GRI MultiSite Project. In SPE Annual Technical Conference and Exhibition, Denver, Colorado. SPE 36450 . 
Warpinski, N. R. (2014, June 1-4)). A review of hydraulic-fracture induced microseismicity. In Proceedings 48th US Rock Mechanics Symposium, Minneapolis, MN, USA. ARMA 14-7774.

Warpinski, N. R. and L. W. Teufel (1987). Influence of geologic discontinuities on hydraulic fracture propagation. Soc. Pet. Eng. J. 39(2), 209-220.

Weijers, L. (1995). The near-wellbore geometry of hydraulic fractures initiated from horizontal and deviated wells. Ph. D. thesis, Delft University of Technology.

Weijers, L. and C. J. de Pater (1992, 26-27 February). Fracture reorientation in model tests. In SPE International Symposium on formation damage control, Lafayette, Louisiana, USA. Society of Petroleum Engineers. SPE 23790.

Weijers, L., C. J. de Pater, K. Owens, and H. Kogsbøll (1994). Geometry of hydraulic fractures induced from horizontal wellbores. SPE Production \& Facilities 9(2), 87-92. SPE 25049.

Weng, X. (1993, 3-6 October). Fracture initiation and propagation from deviated wellbores. In SPE Annual Technical Conference and Exhibition, Houston, Texas, USA. SPE 26597.

Wu, K. and J. E. Olson (2013). Investigation of critical in situ and injection factors in multifrac treatments: Guidelines for controlling fracture complexity. In SPE Hydraulic Fracturing Technology Conference, The Woodlands, Texas. SPE 163821.

Wu, R., A. Bunger, R. Jeffrey, and E. Siebrits (2008, June 29-July 2). A comparison of numerical and experimental results of hydraulic fracture growth into a zone of lower confining stress. In Proceedings 2nd U.S.-Canada Rock Mechanics Symposium, San Francisco, USA. Paper No. 08-267.

Xu, G. and S. Wong (2013, 26-28 March). Interaction of multiple non-planar hydraulic fractures in horizontal wells. In IPTC 2013: International Petroleum Technology Conference, Beijing, China. IPTC 17043-MS.

Zhang, Z., R. G. Jeffrey, A. P. Bunger, and M. Thiercelin (2011). Initiation and growth of a hydraulic fracture from a circular wellbore. Int. J. Rock Mech. Min. Sci. 48, 984-995. 